\title{
LOW COST HYDROGEN PRODUCTION PLATFORM
}

\author{
Final Report \\ August 2001 - December 2007 \\ Phase I and II Completed
}

Timothy M. Aaron \& Jerome T. Jankowiak

Praxair, Inc.

Date Published - September 2009

\author{
PREPARED FOR THE UNITED STATES \\ DEPARTMENT OF ENERGY \\ Under Cooperative Agreement \\ No. DE-FC36-01G011004
}




\section{Program Participants:}

Praxair, Inc. (Program Lead)

175 East Park Drive

Tonawanda, NY 14150

Primary Contact:

Timothy M. Aaron (Primary Contact)

Senior Engineer

Phone: (716) 879-2615

Fax: (716) 879-7567

e-mail: tim aaron@praxair.com

Boothroyd Dewhurst Inc. (Subcontractor)

138 Main Street

Wakefield, RI 02879

Primary Contact:

Nicholas P. Dewhurst

Manager of Implementation and Consulting Services

Phone: (401) 783-5840

Fax: (401) 783-6872

e-mail: ndewhurst@dfma.com

Diversified Manufacturing Inc. (Subcontractor)

410 Ohio Street

Lockport, NY 14094

Primary Contact:

Jerry Wild

Director of Product \& System Administration

Phone: (716) 434-5585

Fax: (716) 434-1757

e-mail: jwild@dmimfg.com 


\section{Contents}

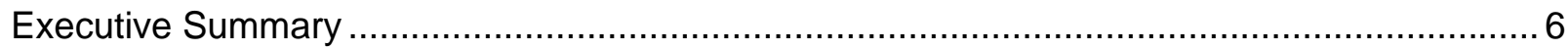

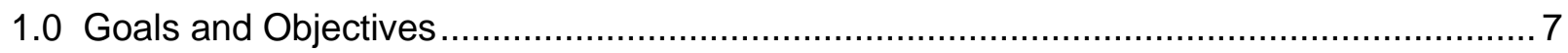

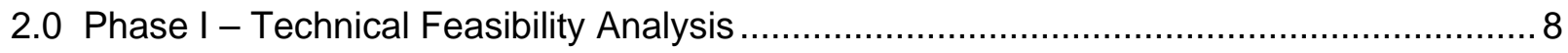

2.1 Concept Definition and Feasibility Analysis ....................................................... 8

2.2 Preliminary DFMA Design and Performance Estimates .................................... 10

2.3 Preliminary DFMA Cost Estimates \& Analysis of Impact of Units Produced on the Cost of

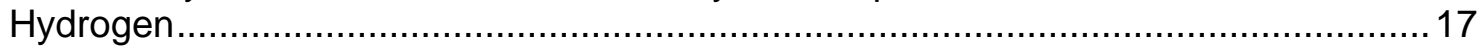

2.4 Market Analysis \& Business Profitability Analysis.............................................. 20

3.0 Phase II - Component Testing and Modeling ..................................................... 24

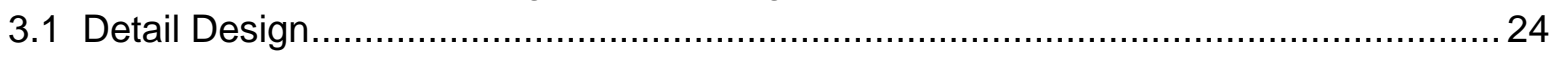

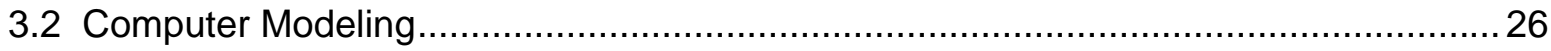



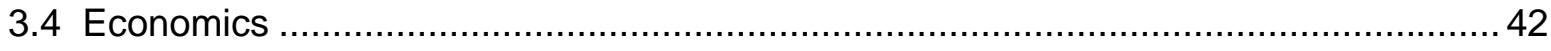

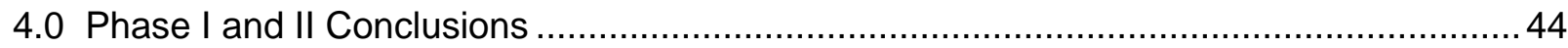

5.0 Phase III - Prototype Testing and Fueling Station Integration.................................... 44

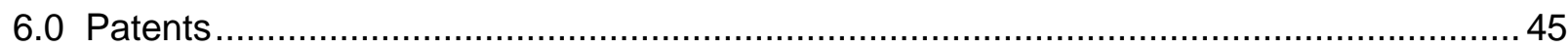

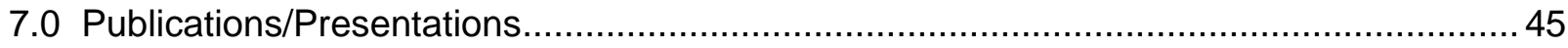

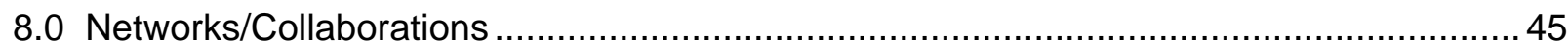

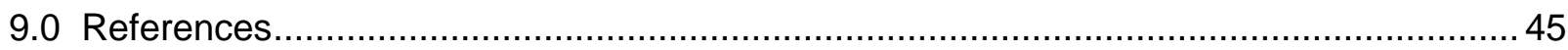

\section{Tables}

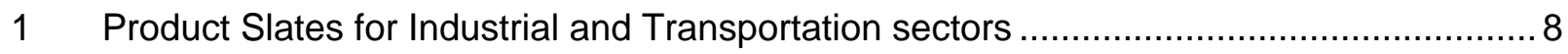

2 Financial Parameters ....................................................................................... 19

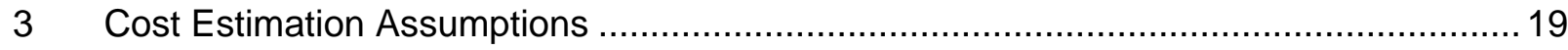

4 Assumptions for Fuel Cell Cars Market......................................................... 21

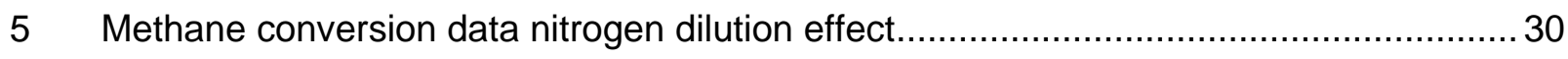

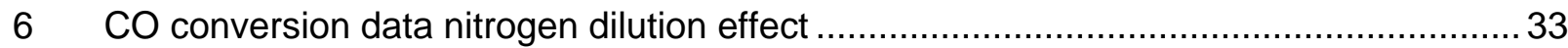

$7 \quad$ Ranges of process conditions studied and full scale design values ............................ 35

8 Experimental matrix for the full scale component tester ...................................... 36

9 Experimental matrix for the full scale component tester with shielding .......................40 


\section{Figures}

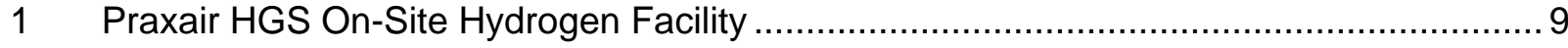

2 PFD - High Pressure Reformer and PSA Purification ................................................ 10

3 PFD - High Pressure Reformer and Membrane Purification ....................................... 10

$4 \quad$ PFD - Low Pressure Reformer, Syngas Compression and PSA Purification ................... 11

5 PFD - Low Pressure Reformer, Syngas Compression and Membrane Purification ........ 11

6 Comparison of Parts and Welds for Various High Temperature Component Concepts . 14

7 Comparison of Weights and Material Costs for Various Concepts ............................... 15

8 Low Cost Hydrogen Production Platform Skid ……................................................ 17

$9 \quad$ Normalized Cost Compare of Various Reformer Concepts ......................................... 18

10 Unit Hydrogen Cost versus Units Produced and System Capacity................................22

11 Unit Hydrogen Cost versus Units Produced and System Capacity (utilities separated) . 20

12 Projections for Hydrogen-Fueled Fuel Cell Cars in the U.S. .......................................22

13 Projections for Hydrogen Fueled Fuel Cell Buses in the U.S.....................................2 23

14 Total Number of $4.8 \mathrm{~kg} / \mathrm{h}$ Praxair Plants Conservative and Optimistic Projections.........2 23

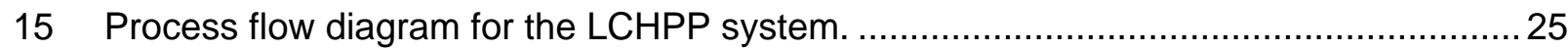

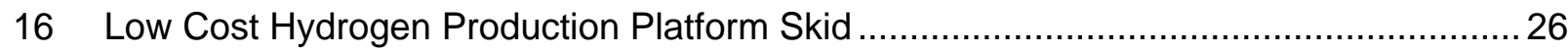

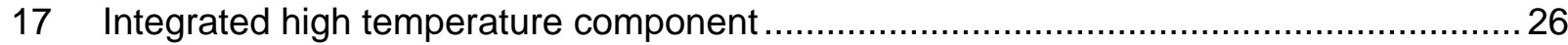

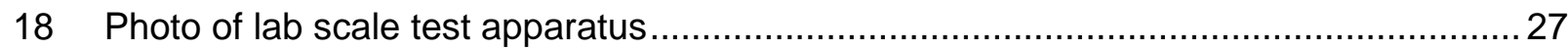

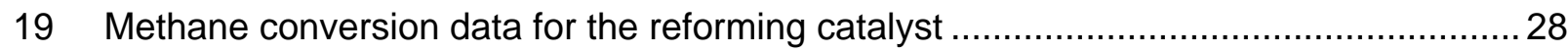

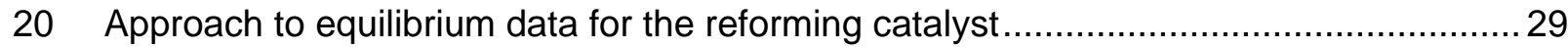

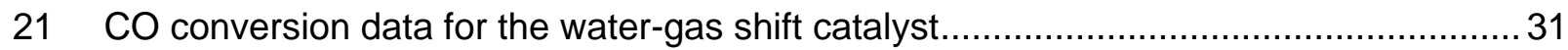

22 Approach to equilibrium data for the water-gas shift catalyst.......................................32

23 Process flow diagram for the full scale component test apparatus ................................34

24 Small hydrogen system component test apparatus installed at Praxair...........................34

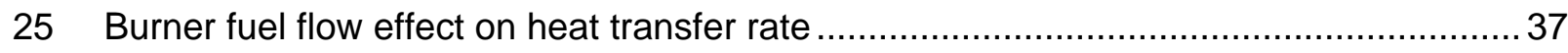

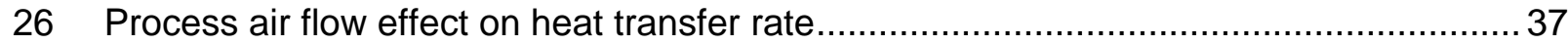

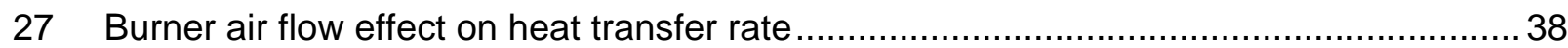

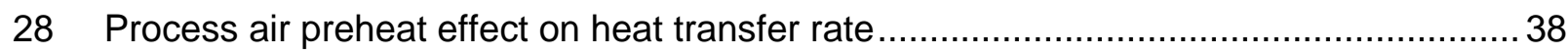

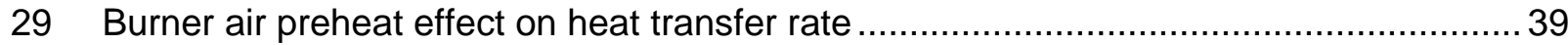

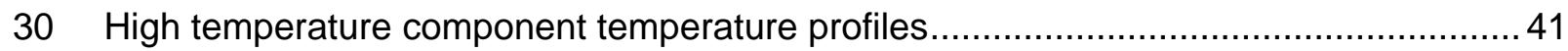

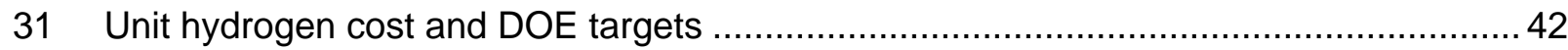

32 Unit hydrogen cost with multiple $4.8 \mathrm{~kg} / \mathrm{h}$ systems ……........................................... 43

33 Unit hydrogen cost on a gallon of gas equivalent basis ........................................... 43 


\section{List of Abbreviations}

DFMA Design for Manufacturing and Assembly

BDI Boothroyd-Dewhurst Incorporated (Subcontractor)

DMI Diversified Manufacturing Incorporated (Subcontractor)

HGS Praxair Hydrogen Generation System (28-72 kg/h Praxair SMR system)

PFD Process flow diagram

P\&I Process and Instrumentation diagram

SMR Steam Methane Reformer

PSA Pressure Swing Adsorption

SCFH Standard Cubic Feet per Hour

SLPM Standard Liters per Minute

GHSV Gas Hourly Space Velocity

HHV Higher Heating Value

LHV Lower Heating Value

ICEV Internal Combustion Engine Vehicle

FCV Fuel Cell Vehicle

LCHPP Low Cost Hydrogen Production Platform (DOE Program Title)

CFD Computational fluid dynamic

GC Gas Chromatograph

ZEV Zero Emission Vehicle

CARB California Air Resources Board 


\section{Executive Summary}

A technology and design evaluation was carried out for the development of a turnkey hydrogen production system in the range of $2.4-12 \mathrm{~kg} / \mathrm{h}$ of hydrogen. The design is based on existing SMR technology and existing chemical processes and technologies to meet the design objectives. Consequently, the system design consists of a steam methane reformer, PSA system for hydrogen purification, natural gas compression, steam generation and all components and heat exchangers required for the production of hydrogen.

The focus of the program is on packaging, system integration and an overall step change in the cost of capital required for the production of hydrogen at small scale. To assist in this effort, subcontractors were brought in to evaluate the design concepts and to assist in meeting the overall goals of the program. Praxair supplied the overall system and process design and the subcontractors were used to evaluate the components and system from a manufacturing and overall design optimization viewpoint. Design for manufacturing and assembly (DFMA) techniques, computer models and laboratory/full-scale testing of components were utilized to optimize the design during all phases of the design development.

Early in the program evaluation, a review of existing Praxair hydrogen facilities showed that over $50 \%$ of the installed cost of a SMR based hydrogen plant is associated with the high temperature components (reformer, shift, steam generation, and various high temperature heat exchange). The main effort of the initial phase of the program was to develop an integrated high temperature component for these related functions. Initially, six independent concepts were developed and the processes were modeled to determine overall feasibility. The six concepts were eventually narrowed down to the highest potential concept. A US patent was awarded in February 2009 for the Praxair integrated high temperature component design.

A risk analysis of the high temperature component was conducted to identify any potential design deficiency related to the concept. The analysis showed that no fundamental design flaw existed with the concept, but additional simulations and prototypes would be required to verify the design prior to fabricating a production unit. These identified risks were addressed in detail during Phase II of the development program.

Along with the models of the high temperature components, a detailed process and 3D design model of the remainder of system, including PSA, compression, controls, water treatment and instrumentation was developed and evaluated. Also, in Phase II of the program, laboratory/fullscale testing of the high temperature components was completed and stable operation/control of the system was verified. The overall design specifications and test results were then used to develop accurate hydrogen costs for the optimized system. Praxair continued development and testing of the system beyond the Phase II funding provided by the DOE through the end of 2008. This additional testing is not documented in this report, but did provide significant additional data for development of a prototype system as detailed in the Phase III proposal.

The estimated hydrogen product costs were developed (2007 basis) for the $4.8 \mathrm{~kg} / \mathrm{h}$ system at production rates of $1,5,10,100$ and 1,000 units built per year. With the low cost SMR approach, the product hydrogen costs for the $4.8 \mathrm{~kg} / \mathrm{h}$ units at 50 units produced per year were approximately $\$ 3.02$ per $\mathrm{kg}$. With increasing the volume production to 1,000 units per year, the hydrogen costs are reduced by about $12 \%$ to $\$ 2.67$ per $\mathrm{kg}$. The cost reduction of only $12 \%$ is a result of significant design and fabrication efficiencies being realized in all levels of production runs through utilizing the DFMA principles. A simplified and easily manufactured design does not require large production volumes to show significant cost benefits. These costs represent $a$ significant improvement and a new benchmark in the cost to produce small volume on-site hydrogen using existing process technologies. The cost models assume a natural gas cost of \$5/MMBtu (HHV). 
Praxair has, in Phases I and II of this program, shown that significant improvements in cost, plant layout, system integration and overall system optimization are achievable. Phase III of the program, submitted in January 2007, was to focus on demonstrating both the technical feasibility and economic viability of the design developed in Phases I and II through a full-scale prototype design, construction, installation, analysis and operation at a hydrogen fueling station. Due to funding limitations, Phase III of the program was not approved by the DOE.

\subsection{Goals and Objectives}

\section{Program Goal}

To commercialize a safe, robust, cost effective, small scale $(2.4-12 \mathrm{~kg} / \mathrm{h})$, hydrogen production system using advanced packaging and design methodologies. The system is based on traditional steam methane reforming (SMR) process technology. The approach involves applying Design For Manufacturing and Assembly (DFMA $\left.{ }^{\circledR}\right)$ techniques, as well as a high level of system design/integration, to lower the cost to produce hydrogen from small on-site plants. The applications for the system include both the transportation and industrial hydrogen market.

\section{Phase I Objective}

Develop a system design(s) and economic models to validate the overall system approach. Define the DFMA-based SMR system in sufficient detail to assess the overall viability of a business based on the transportation and industrial markets. Use the subcontractors, Boothroyd-Dewhurst (BDI) and Diversified Manufacturing (DMI) to assist in implementing DFMA and to evaluate the feasibility of the design concepts.

\section{Phase II Objective}

The initial effort in Phase II was to complete the detail design of the concept and related auxiliary components. This information was then used to generate heat transfer and reaction kinetic models as well as the stress and thermal engineering models of the system. The test plan and component test apparatus for the key components was also developed from the detailed design. A large portion of the program was associated with component testing and converging the prototype tests with the reactor and system computer models to define the optimum system design and the operating parameters.

At the conclusion of Phase II, a detailed design was developed and proven through computer modeling and component testing. The economic models were updated to reflect all system modifications. With the successful design and economic development in Phase II, Phase III was to concentrate on building and testing a prototype / demonstration unit as well as developing any tooling or infrastructure required for producing the system in the quantities required to meet the market demand.

The Phase II effort included the team members from Phase I, Praxair, Boothroyd-Dewhurst (BDI) and Diversified Manufacturing (DMI) and with involvement from a catalyst supplier and a heat transfer/reaction kinetics modeling consultant. Praxair has the overall program lead and is responsible for the development and testing of the prototype components. BDI assisted in the area of design optimization concentrating on components outside of the high temperature component. Diversified Manufacturing (DMI) provided cost estimating for the components as well as advice on manufacturing processes and system design and fabrication. The catalyst supplier assisted in choosing both the catalyst composition and configuration. The heat transfer/reaction kinetics consultant reviewed the high temperature component concept and provided design guidance to this critical area of the system. The members of this team have expertise in all the critical design areas required to successfully define an optimized, low cost system for Phase III. 


\subsection{Phase I - Technical Feasibility Analysis}

The product slates for small-scale hydrogen plant in transportation and industrial sectors are defined in table 1.

\begin{tabular}{|l|c|c|}
\hline \multicolumn{3}{|l|}{ Table 1. Product Slates for Industrial and Transportation Sectors } \\
\hline & Industrial Sector & Transportation Sector \\
\hline Product flow rate, $\mathrm{kg} / \mathrm{h}$ & $1.2-85$ & $2.4-12$ \\
\hline Delivery pressure, psig & 125 & 7,500 \\
\hline Natural gas supply pressure, psig & $5-200$ & $1-20$ \\
\hline $\mathrm{H}_{2}$ purity, \% & 99.99 & $99+$ \\
\hline Impurities, ppm max & & $\mathrm{NA}$ \\
\hline $\mathrm{N}_{2}$ & 100 & $<10$ \\
\hline $\mathrm{CO}$ & $<10$ & $\mathrm{NA}$ \\
\hline $\mathrm{CO}_{2}$ & 3 & $\mathrm{NA}$ \\
\hline Total hydrocarbons & 10 & \\
\hline
\end{tabular}

Small volumes of hydrogen are required by customers in fats and oils, float glass, utilities, chemicals, electronics and metals industries. A majority of these customers are supplied with liquid hydrogen. However, most of them need hydrogen in gaseous form. Therefore, a significant number of opportunities exist, if a small on-site plant can supply hydrogen to these customers at cost lower than liquid.

In the transportation sector, refueling facilities for fuel cell vehicles (FCVs) will require small onsite hydrogen plants. A typical gas station refuels 200 cars per day or supports 1800 cars over a 9-day refilling cycle for a typical passenger car. A small plant producing $2.4-12 \mathrm{~kg} / \mathrm{h}$ hydrogen will be able to refuel 11 to 55 cars per day (or support 100 to 500 cars over the complete refueling cycle). For the average gas station, this range will represent 5 to $25 \%$ of the total automotive traffic.

Most of the industrial customers require minimum 99.99\% purity. General limitations on impurities are listed in Table 1. For $\mathrm{H}_{2} \mathrm{FCV}, \mathrm{CO}$ can be detrimental to the fuel cell. Although other impurities do not poison the fuel cell, overall hydrogen purity must be high so that the fuel cell can be operated with high hydrogen utilization rate. Therefore, an overall purity of $99 \%$ is targeted for this program.

The pressure requirement for a majority of industrial customers is below 200 psig. In the transportation sector, the pressure required will depend on whether it is stored as high-pressure gas or as a low-pressure alternative such as a metal hydride. For storage of 7,500 psig hydrogen on-board, the refueling station will have to store hydrogen above 8,000 psig for quick refueling.

The Phase I analysis was limited to estimating the cost of producing hydrogen at the pressure attained from the PSA Purification system, 100 - 125 psig. Three production capacities were selected for economic feasibility analysis: $2.4,4.8$ and $12 \mathrm{~kg} / \mathrm{h}$.

\section{1 - Concept Definition and Feasibility Analysis}

Praxair has significant experience in the on-site production of hydrogen and a thorough understanding of the issues associated with the design, fabrication, field construction, start-up and operation of SMR based hydrogen facilities. A review of large SMR based hydrogen facilities $(>2,400 \mathrm{~kg} / \mathrm{h})$ shows that they are driven by the cost of utilities (approximately $80 \%$ utility cost and $20 \%$ installed and operational capital). This ratio affords additional capital and project dollars to reduce utility consumption and increase overall plant efficiency. To that end, large SMR plant designs are driven by process requirements and only secondary attention is 
given to capital and project reductions. This approach works well with large hydrogen facilities, but as the capacity decreases, the capital component increases toward $80 \%$ capital cost and only $20 \%$ is associated with the utilities. This means that an entirely different approach must be taken to make small on-site hydrogen facilities an economical option.

In the mid 1990s, Praxair developed the smallest industrial SMR based on-site hydrogen production system called the HGS (see figure 1). This system was designed to significantly lower the cost to generate hydrogen for small industrial users. The LCHPP goals require a system with $1 / 10$ the capacity and plot size and an overall lower hydrogen unit cost than the HGS concept. These goals represent another step change from the innovations of the HGS system and will require new concepts such as DFMA and maximizing the level of component and system integration.

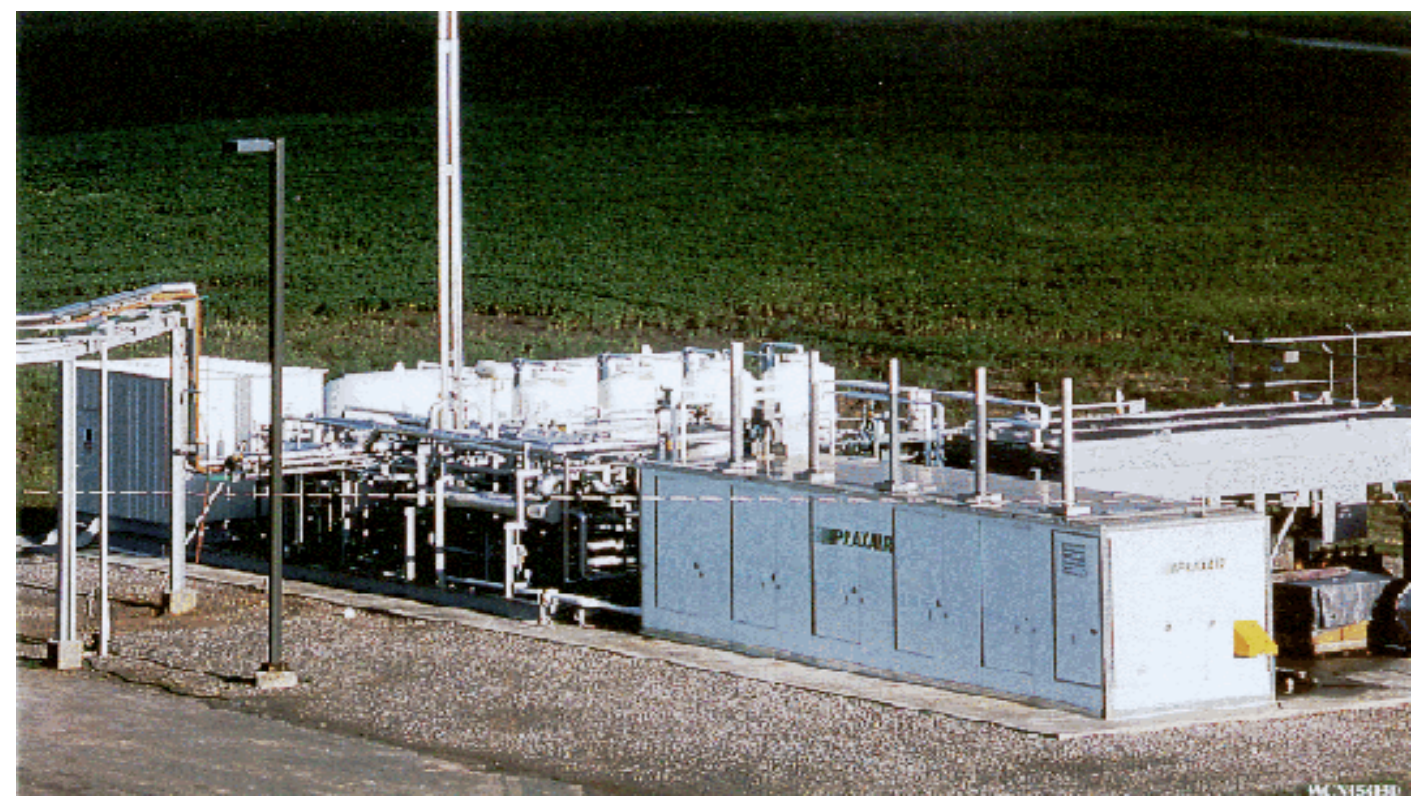

Figure 1. Praxair SMR based on-site hydrogen facility at Seymour, IN (72 kg/h system). Although the system is still large, this type of system is highly skidded resulting in less than a 4 week schedule from delivery of plant to start-up of the system. Overall plot size is $50^{\prime} \times 100$ '.

The initial effort of the LCHPP program was to define the overall operating parameters for the system including product and utility requirements (see table 1). After these items were defined, the next step was to review existing SMR based hydrogen facilities and associate a cost percentage breakdown to the various components that make-up an on-site hydrogen production facility. This data would then be used to direct the efforts to the highest potential capital cost reductions and also serve as a benchmark for the system development.

The plants evaluated ranged in size from $45 \mathrm{~kg} / \mathrm{h}$, similar to the plant shown in figure 1, to over $2,400 \mathrm{~kg} / \mathrm{h}$. From this analysis a cost component percentage breakdown was developed and goals were set for the development program. From the data, it became clear that the reformer and related high temperature components account for the largest portion of the capital cost of an on-site hydrogen facility. Based on this information, a large portion of the initial development effort was allocated to reduce the overall capital related to this equipment. Also of note, the physical size of the equipment required for large SMR plants means that the erection costs is over $50 \%$ of the overall cost and the plant can take over a year to construct (from pouring foundations to supplying hydrogen). 


\section{2 - Preliminary DFMA Design and Performance}

Various high temperature process options based on an integrated system design utilizing DFMA design techniques were developed. Based on the preliminary assessment, three different high temperature component design concepts were selected as having the highest potential of approaching the overall program goal. Based on the initial feasibility assessment, it was determined that, from a mechanical perspective, all of these system concepts were viable. Therefore, an initial process and energy assessment was made for each of the concepts. The production capacity of $4.8 \mathrm{~kg} / \mathrm{h}$ hydrogen was used for the assessment. Once the process models were completed and the estimated component sizes were determined, each concept was further analyzed by creating a detailed 3D model. These models were then reviewed from a DFMA perspective and from a general material and fabrication analysis. A technical and economical feasibility evaluation of these options was then completed.

\subsubsection{Process Design}

The baseline design criteria set forth in the DOE proposal defined the system as an SMR based unit that utilizes existing process technologies. The understanding that the reformer and related high temperature components accounted for the largest portion of the total cost indicated that maximum effort should be expended on developing the lowest cost and most integrated approach to these components. To start this effort, other factors outside of the high temperature components must be understood and, at least to an initial level, optimized. Conclusions reached on the auxiliary components (mainly compression and purification systems) set many of the parameters necessary to design the high temperature components. Several of the initial process flow diagrams for the system are shown in figures 2-5.

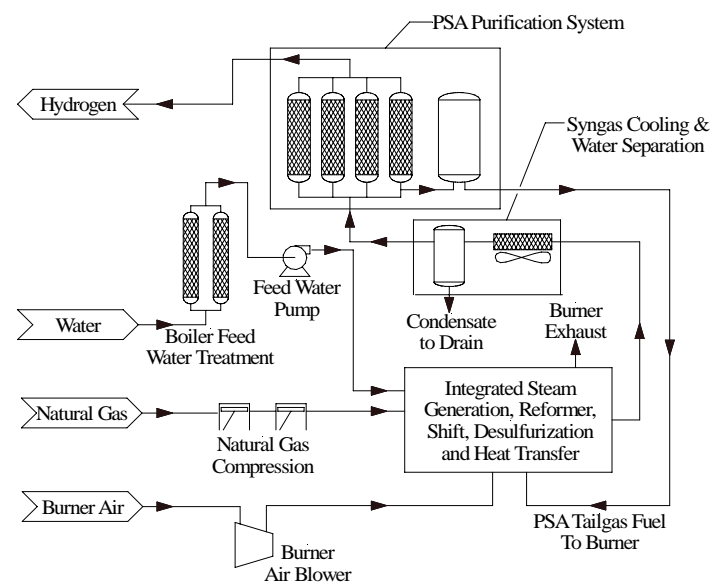

Figure 2. PFD showing high pressure reformer (>120 psig) and PSA purification system.

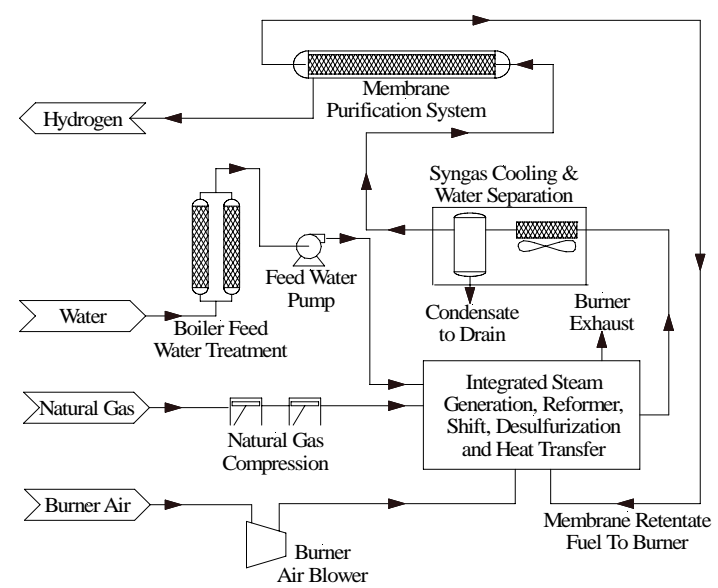

Figure 3. PFD Showing high pressure reformer (>120 psig) and membrane purification system 


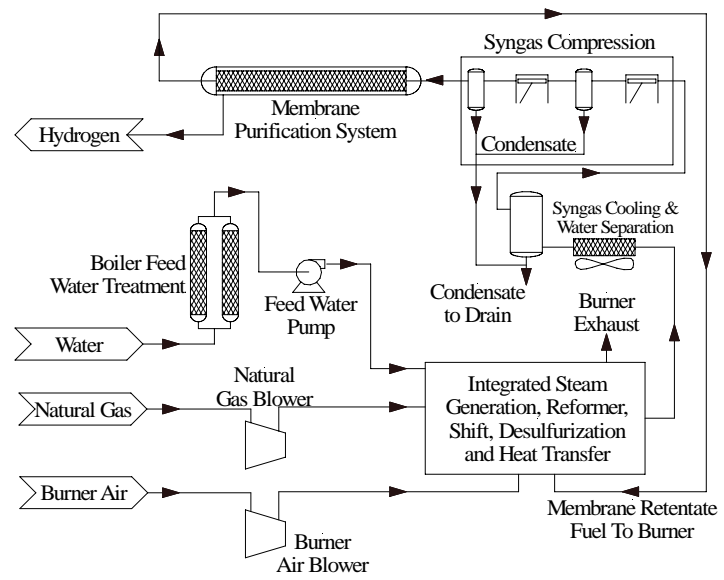

Figure 4. PFD showing low pressure reformer ( $<15$ psig), syngas compression and PSA purification.

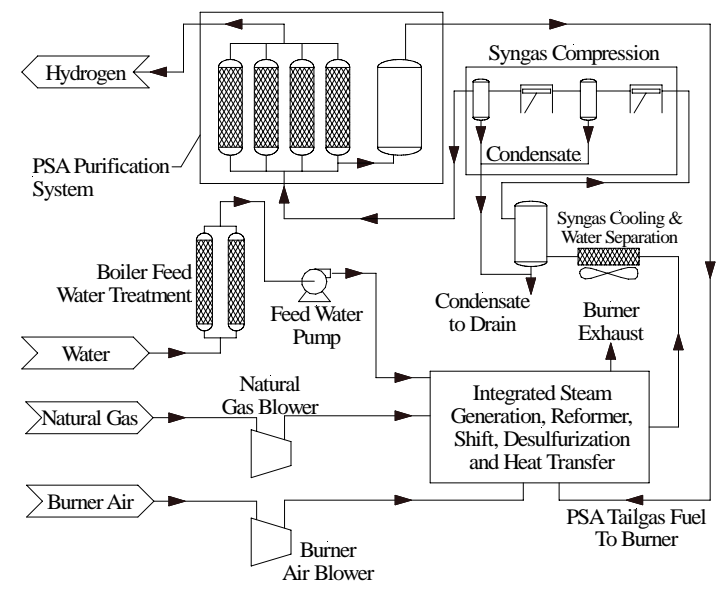

Figure 5. PFD showing low pressure reformer (<15 psig), syngas compression and membrane purification.

Feed water is filtered and treated in a water treatment system. The treated water is pumped to approximately 150 psig and delivered to the high temperature component where steam is generated by using the remaining heat in the burner exhaust after the reforming step. Natural gas is compressed in either a blower (figures $4 \& 5$ ) or a compressor (figures $2 \& 3$ ) and delivered to the high temperature component. The natural gas is then mixed with a small amount of hydrogen (not shown) and sent through the desulfurizer vessel. Superheated steam and desulfurized natural gas are mixed and fed to the reformer catalyst. The burner exhaust is used to provide the heat required for the reforming process. Air from the blower is compressed to approximately 2 psig and preheated using heat from the syngas heat exchange and the shift reactor. The syngas exiting the high temperature component requires water removal prior to being sent to the PSA for purification. Catalyst is incorporated in both the reformer and shift reactors.

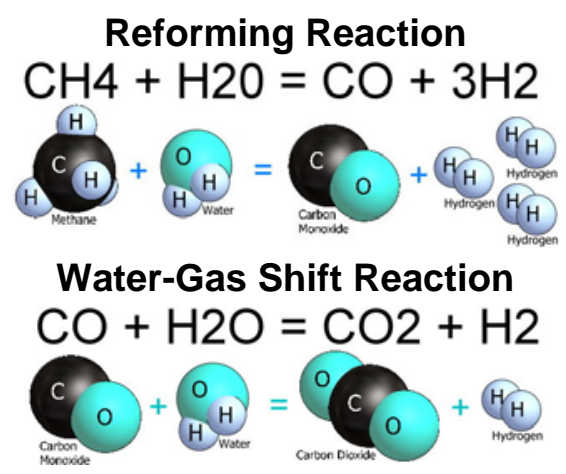

The cooled syngas from the separator is then sent to the purification system. If low pressure reforming, as shown in figures $4 \& 5$, is utilized, a compressor will be required to compress the syngas to approximately 120 psig for the PSA or membrane purification system. The purification system, either membrane (figures $3 \& 5$ ) or PSA (figures $2 \& 4$ ) is then used to purify the hydrogen. The constituents removed by the purification system include $\mathrm{CO}, \mathrm{CO}_{2}, \mathrm{CH}_{4}$ and water. The waste gas from the purification system is then used in a burner to supply the heat required for the process. 


\subsubsection{Process Design Parameters}

After completing the PFDs of multiple system concepts, the next item was to address options for each of the auxiliary components, factoring in the high temperature component design, the initial parameters for pressure, flow and composition. Below are listed some of the selection criteria and conclusions for several system components.

- Syngas/Natural Gas Compression - The first major design parameter evaluated was the desired operating pressure for the system components and the optimum compression configuration. Design considerations related to the compression equipment include the following:

- The high operating temperature of SMR components generally dictate that lower pressure allows for the use of lower cost alloys for the materials of construction.

- Lower system operating pressure results in higher velocity for a given pipe/component size which in turn increases pressure drop and overall system and component sizes.

- $\quad$ The purification system, either PSA (figures 2 and 4) or membrane (figures 3 and 5) generally require syngas pressures greater than 120 psig.

- Natural gas compressors are well understood and off-the-shelf components that do not require significant modifications to operate in this type of system.

- Syngas compressors are custom components and require inter-stage condensate removal and materials of construction suitable for compressing a wet and corrosive gas. Praxair operational experience has found that these machines are generally a costlier, higher maintenance component when compared to natural gas compressors.

- The amount of gas flow in the syngas compressor is about 3 times that of the equivalent natural gas flow. This means the syngas compressor requires approximately 3 times the power of the natural gas compressor, generates significantly more heat and requires a larger space in the overall system package.

- Conclusion - Natural gas compression was determined to be the preferred choice. The high temperature component was designed to operate at a pressure sufficient for the purification system.

- Purification System - The hydrogen purification system options included polymeric/palladium membrane separation (figures $3 \& 5$ ) or PSA purification (figures $2 \& 4$ ). Design considerations related to the include the following:

- Membrane system has fewer moving parts.

- Product hydrogen from a membrane is on the permeate side at low pressure requiring product compression from near atmospheric pressure. Hydrogen product pressure from a PSA system is only slightly lower than the inlet pressure to the PSA system (pressure drop across the PSA bed).

- A polymeric membrane is not capable of producing product hydrogen at the specifications required for the system.

- Palladium membranes have not been commercially proven in syngas service and therefor do not meet the system requirement of using existing commercial process technology.

- Conclusion - Existing membrane technology either does not meet the criteria that all components be existing commercially developed processes or, in the case of polymeric membranes, does not meet the product hydrogen specification. Additional hydrogen compression required with the membrane purification significantly increases the capital cost of the system as well as the power and maintenance cost. PSA purification was determined to be the preferred choice. 
To evaluate the system, process models were created using HYSYS process simulator. These models showed the overall heat, flow and pressures required for various components and processes. This data was then used for initial development of the mechanical concepts and was updated throughout the design process.

The overall efficiency of the plant is defined as follows:

$$
\text { Efficiency }=\frac{\text { Energy Recovered in } \mathrm{H}_{2}(\mathrm{HHV}) \times 100}{\text { Energy Input in Natural Gas }(\mathrm{HHV})}
$$

Based on this definition, a system efficiency of $65.5 \%$ (HHV) was calculated. In comparison, large SMR systems achieve 80 - 85\% efficiency (HHV) depending on the production. The main reason for the lower efficiency of the small-scale plant is higher heat losses from the small reactor on a percentage basis and lower purification system recovery due to the lower operating pressure. Large scale reformers typically operate at pressures as high as 400 psig. Another reason for high efficiency of large-scale SMR plants is co-production of steam for export.

\subsubsection{Reformer, Shift, Steam Generation and Related Components}

After setting the parameters for the system ins/outs and with utilizing detailed HYSYS process flow models, the next step was to develop mechanical design concepts for the system. As previously detailed, the high temperature components, consisting of the reformer, shift, steam generation and related components has the highest cost contribution to the overall project cost. The initial efforts centered on reducing this capital cost by applying the following:

- Use DFMA design principles. Reduce the part count and complexity of the system. Limit the quantity of unique parts in the system.

- Welded construction. Cost targets do not permit a large number of bolted and flanged connections. Piping and component assembly will need to be robust and have sufficient life as to not require field removal and repair. A large portion of Phase II focused on verification of the concepts and providing the design information to allow for welded construction.

- Integration. Traditional reformers tend to be modular designs with separate reformer, shift, heat exchange and steam generation. For this system to achieve the design goals, items will need to be integrated, thus reducing the amount of piping, the number of connections, the amount of insulation and the assembly time.

- Small System. This system is designed as a gas station size unit and minimizing the plot size is a key component to the program. The system must be designed as a single skid, easily installed unit.

Using this criterion, six potential concepts were developed. The concepts ranged from highly integrated systems to mass produced component designs with varying modes of heat transfer and geometry. The HYSYS process models were adjusted to reflect each of these designs and each concept was evaluated based on overall mechanical and process feasibility. Initial analysis showed that 3 of the concepts were either insufficient in heat transfer area or the heat transfer area required was too large to meet the small easily installed system criteria.

The three highest potential concepts were then 3D modeled to the individual part level. The subcontractors were an integral part of the design team during this phase. Diversified Manufacturing reviewed each of the designs from a low scale fabrication and manufacturing standpoint. Boothroyd-Dewhurst reviewed the design from a larger production volume and developed cost estimates based on streamlined automated production runs. All of these efforts 
were combined to develop a complete cost and system analysis for the integrated high temperature components.

The development of the high temperature component concepts evolved along two distinct paths. The first two concepts, referred to here on as concepts alpha and beta, were developed to maximize the system integration and to reduce the overall part count and system size. The third concept, referred to here on as concept gamma, was developed to minimize unique parts, but not necessarily the overall part count or the level of integration. It was hoped that all high temperature component operations could be done in identical units, then the scale of economies associated with the production of these individual components would reduce the unit cost to a point where it matched or compared favorably to the integrated concepts.

\section{Reformer \& Hot Components Matl Cost Compare}

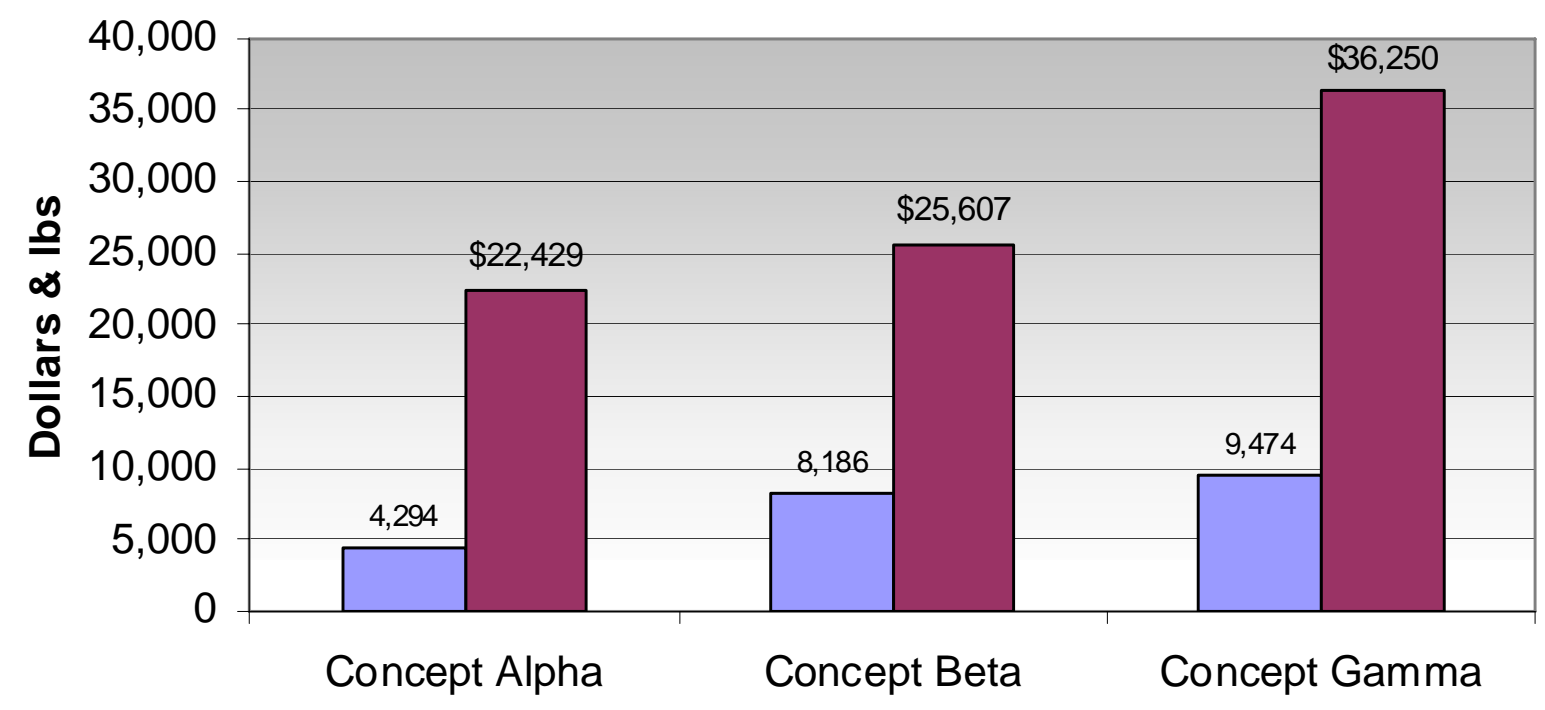

$\square$ Weight (lbs) $\quad \square$ Matl Cost (\$)

Figure 6. Comparison of parts and welds for various high temperature component concepts (2003). 


\section{Low Cost Hydrogen Reformer Options}

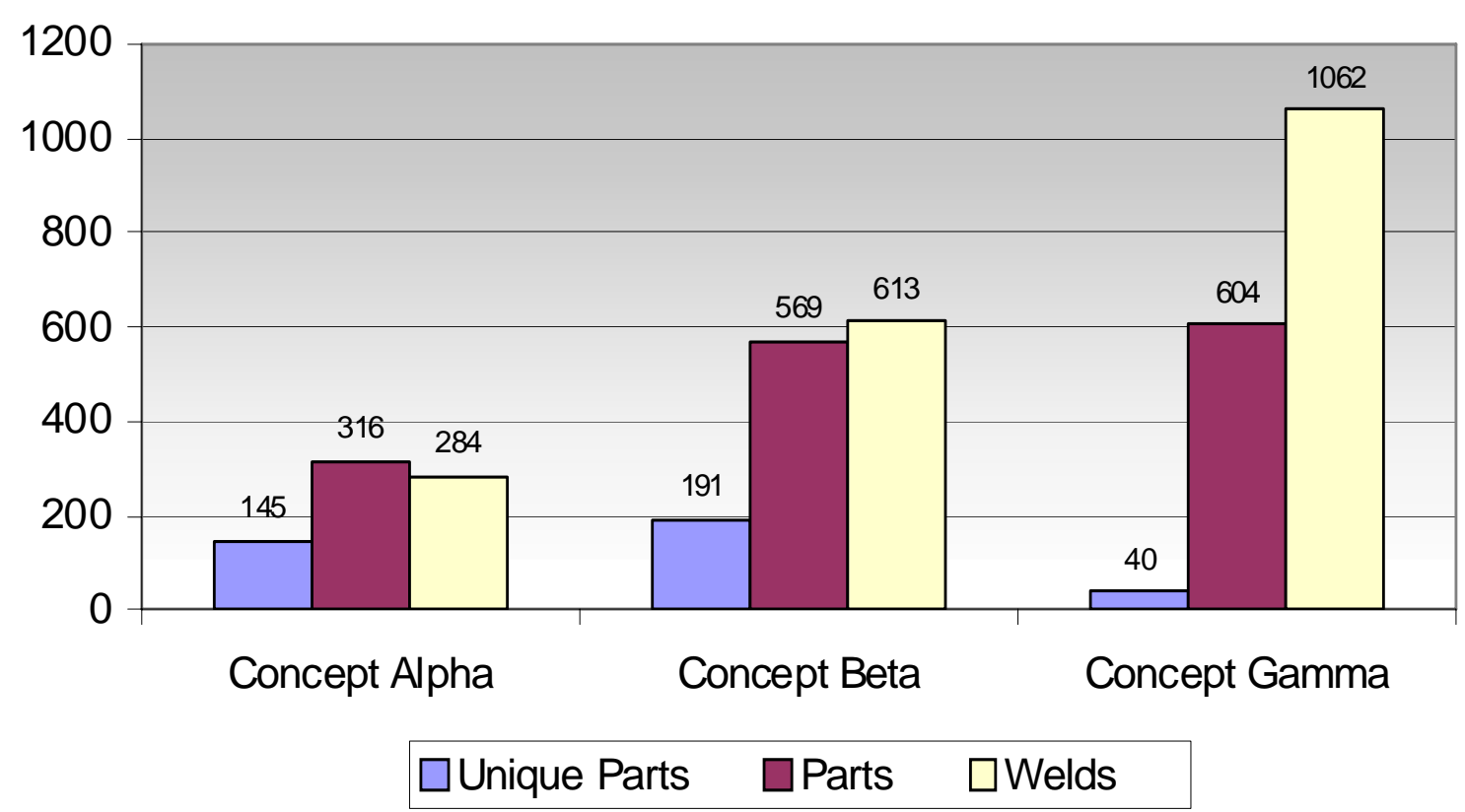

Figure 7. Comparison of weights and material costs for various high temperature component concepts.

As shown in figure 7, the gamma concept reduced the number of unique parts by more than a factor of three over the alpha concept and and a factor of four over the beta concept, but the increase in the total parts and welds resulted in this concept having an overall higher cost than the others. The final cost estimates, including the material costs shown in figure 6 , as well as adding in the manufacturing cost, place the alpha concept with the lowest cost, the beta concept is next costing $10 \%$ more than alpha and the gamma concept costs $80 \%$ more than the alpha concept. These results clearly indicate that minimizing the overall part count and maximizing integration gives the lowest overall component initial cost.

Although these results show a significant step in reducing the high temperature component cost of the SMR based system, there were many additional items that needed to be verified in Phase II of the program prior to developing a working prototype. The lowest initial cost will only yield the lowest overall cost (capital and operational) if the system is fully and completely designed and evaluated prior to entering into a manufacturing program. A compact, welded high temperature component assembly will make servicing of individual internal components, at the operational site, difficult. Consequently, the high temperature components need to be designed for more than 100,000 hours of operation. Phase II of the program focused on addressing concerns documented in the risk analysis of the system and assuring that all risks were mitigated prior to entering Phase III of the program.

\subsubsection{Balance of Plant Components}

The high temperature component analysis showed that the alpha design has the lowest overall cost potential for that portion of the system. Balance of plant components were then specified and selected from commercially available components. Listed below are some of the criteria associated with the selection of the balance of plant items: 
- Hydrogen Purification - The purification system will be a pressure swing adsorption (PSA) design. Praxair developed advanced small hydrogen PSA technology in association with other industrial and DOE sponsored programs. This technology has been incorporated into the LCHPP program.

- Boiler Feedwater - The boiler feedwater system has been designed for use with typical city water specifications and pressures. The system consists of purification/treatment, pump, and flow control components.

- Enclosure - The system is designed as an enclosed skid, capable of being installed in all climates within the continental United States. No additional fencing or personal protection will be required.

- Codes and Standards - All components located on the skid, with the exception of the control panel which is isolated from the process portion of the skid, have been specified to meet the hazardous electrical classification related to hydrogen processing. The process portion of the skid is constantly ventilated using the glycol cooling system fan. The actual inventory of flammable gases within the process skid is less than the amount of gas in a few typical high pressure welding/cutting cylinders.

After having all the system components defined, the next step was to develop a model of the system, complete with all required components, controls and interconnecting piping necessary for the system. The skid package is designed to be a complete, operationally verified system prior to be sent to the site for installation. A diagram of the system skid assembly is shown in figure 8 . 


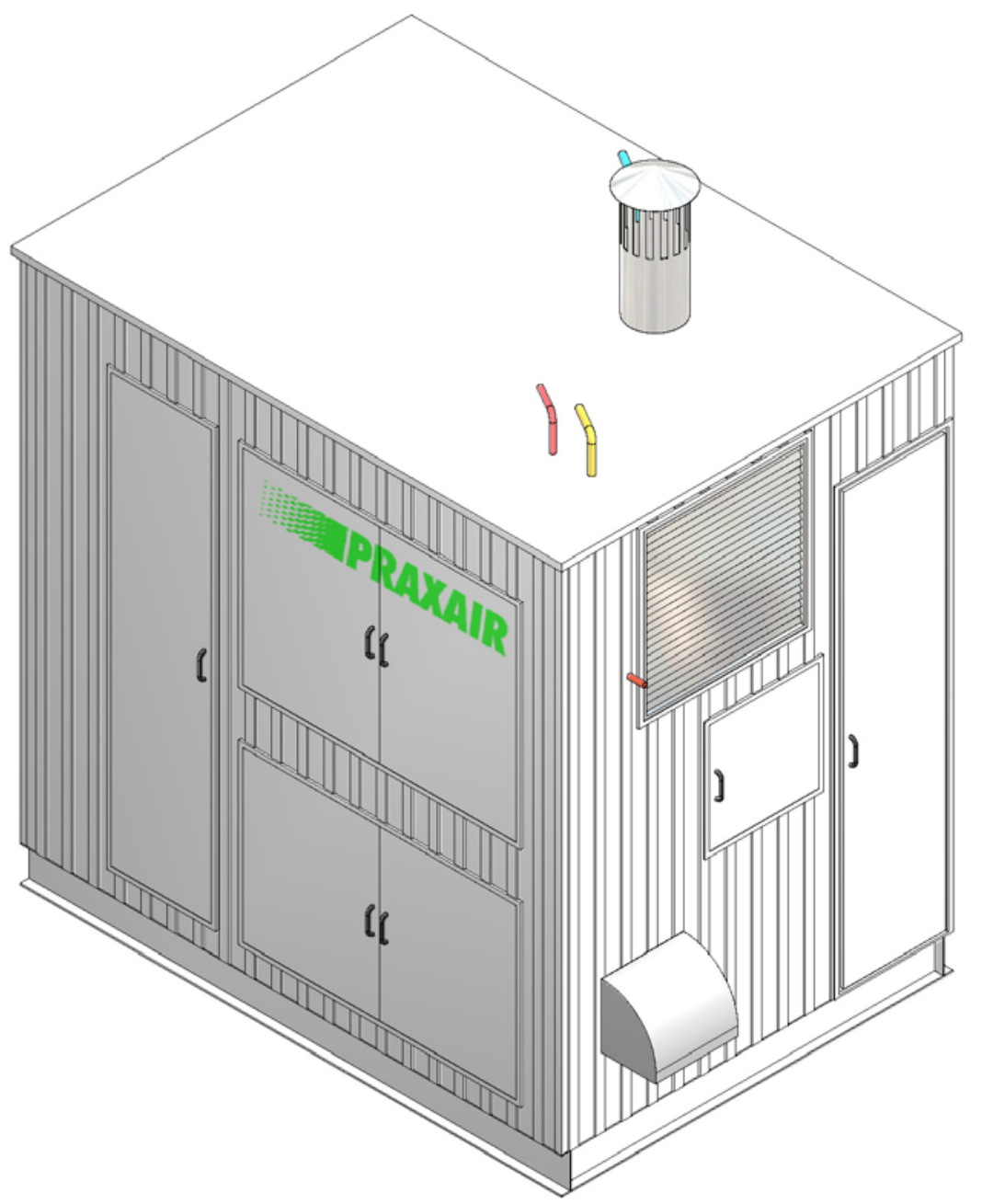

Figure 8. Low Cost Hydrogen Production Platform skid design. All components and controls necessary for the production of $4.8 \mathrm{~kg} / \mathrm{h}$ hydrogen using natural gas, city water and electricity as utilities.

\section{3 - Preliminary DFMA Cost Estimates \& Analysis of Impact of Units Produced}

The $4.8 \mathrm{~kg} / \mathrm{h}$ system shown in figure 8 served as the basis for the overall Phase I economic analysis. Subsequently, product flow rates from 2.4 to $12 \mathrm{~kg} / \mathrm{h}$ were evaluated. The demand in the industrial sector varies widely between 0.5 to $85 \mathrm{~kg} / \mathrm{h}$ (Heydorn, 1998). Plant sizes ranging between 2.4 and $12 \mathrm{~kg} / \mathrm{h}$ could serve these markets as well as the transportation market. The capital costs for $2.4,3.6$ and $12 \mathrm{~kg} / \mathrm{h}$ systems were estimated by using appropriate scale factors. For each capacity, costs were estimated for 1, 5, 10, 25, 100 and 1,000 units built per year. The product costs were estimated and compared with two competing supply options: liquid hydrogen and electrolysis.

The cost to manufacture the $4.8 \mathrm{~kg} / \mathrm{h}$ reformer and related high temperature components was created based on the system design developed in task 1.1. The 3D models of all the individual parts required for the high temperature component assembly (steam generation, reformer, shift, desulfurization and heat transfer) provided detailed design parameters and subsequently detailed cost estimates of the overall component. The 3-D part computer models were transferred directly into Boothroyd-Dewhurst's DFMA analysis program and detailed cost estimates and breakdowns were developed. Diversified Manufacturing's approach to the cost estimate paralleled the traditional part and assembly analysis. In the final conclusion, the analysis by both subcontractors was relatively close with the Boothroyd-Dewhurst analysis 
showing the highest potential cost savings. The cost analysis for the alpha, beta and gamma high temperature component concepts detailed in section 1.1 is shown in figure 9 .

\section{Reformer \& Hot Components Matl Normalized Cost Compare (Percentage of Alpha Concept BDI/DMI Avg)}

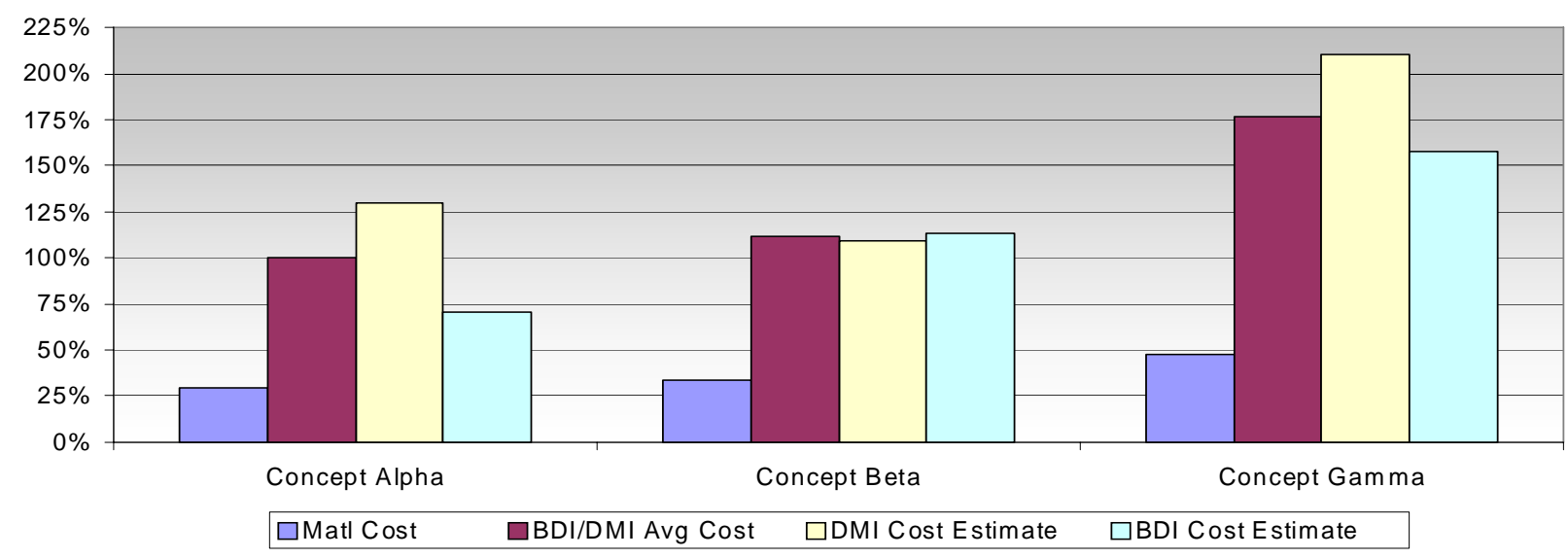

Figure 9. Normalized cost for various reformer concepts.

The average cost estimate of the alpha concept was used as the baseline for overall cost graphs and subsequent system cost estimates (unless noted) presented within this report. Although the alpha concept clearly represents the highest potential for cost reductions through DFMA principles based on the BDI estimatesr, using the average of the DMI/BDI estimates was a more conservative approach over simply using the lowest cost estimate available.

The data shows a slightly lower average cost for the alpha concept with regard to the beta concept, but both the alpha and beta concepts showed a significant cost improvement over the gamma concept. This data, as well as the fact that the gamma concept is a larger more massive system, resulted in down selecting to the alpha and beta concepts.

After down selecting to the alpha and beta concepts, the next evaluation was related to understanding the discrepancy between the BDI and DMI alpha concept cost estimates. BDI indicated that their evaluation was identical for all concepts and the fact that the alpha concept had the least parts and welds, as well as the least amount of machining and assembly time, resulted in their models showing the lowest cost for this approach. DMI indicated that they felt the higher level of integration could result in assembly and fabrication issues that may increase the overall risk related to producing the system. DMI felt that BDI's estimate could be achieved provided a significant effort in prototyping the alpha design and understanding the fabrication and assembly issues was completed prior to fabricating production units. It was therefore felt that the highest potential cost savings for the high temperature component system was with developing the alpha concept.

The cost of the balance of plant equipment (natural gas compressor, water treatment system, air compressor, heat exchangers, water pump and cooling system) was based on purchasing major components from qualified suppliers. The quotes were obtained for multiple unit purchases (in quantities of 10, 100 or 1,000) when available. In other cases, reasonable cost reductions were assumed. A P\&I diagram was developed to define the required controls and instrumentation for safe operation, start-up and shut down of the system. The cost of the control system, control valves and instruments were estimated based on volume pricing available to Praxair. 
Based on the system layout shown in figure 8, the cost of the complete assembly was developed including the costs of piping, insulation, equipment and instrument mounts, electrical and metal enclosure. Finally, engineering, design, shipping, installation and start-up costs were estimated. All these costs are included in the estimate of total capital.

The product costs were defined by adding annual operating, M\&R (maintenance and repair) and capital recovery costs. To estimate capital recovery, the method described in hydrogen infrastructure report (Thomas 1997) was used. The financial parameters listed in tables 2 and 3 were used.

\begin{tabular}{|l|l|}
\hline \multicolumn{2}{|c|}{ Table 2. Financial Parameters } \\
\hline $\mathrm{r}$ & $0.15(15 \%$ after-tax real rate of return) \\
\hline $\mathrm{t}$ & $0.38(38 \%$ corporate tax rate $)$ \\
\hline $\mathrm{n}$ & 15 year plant life (depreciation recovery period) \\
\hline $\mathrm{i}$ & $0.0(0 \%$ inflation rate $)$ \\
\hline
\end{tabular}

\begin{tabular}{|l|l|}
\hline \multicolumn{2}{|l|}{ Table 3. Cost Estimation Assumptions } \\
\hline Natural gas & $\$ 4 / \mathrm{MMBtu}(\mathrm{HHV})$ \\
\hline Power & $\$ 0.05 / \mathrm{kWh}$ \\
\hline Water & $\$ 2.31 / 1000$ gal. \\
\hline M \& R & $3 \%$ of capital investment/year \\
\hline Annual operating factor & $80 \%$ \\
\hline Labor & $\begin{array}{l}15 \% / 2 \% \text { man-yr (@ 1 unit / @ 1000 } \\
\text { units) }\end{array}$ \\
\hline Labor rate & $\$ 40,000 / \mathrm{yr}$ \\
\hline
\end{tabular}

The cost developed in Phase I of the program for the $4.8 \mathrm{~kg} / \mathrm{h}$ hydrogen system ranges from $\$ 2.15$ to $\$ 3.64$ per $\mathrm{kg}$. The contribution of utilities (natural gas, electricity and water) in the overall cost is a constant $\$ 1.00$ per $\mathrm{kg}$. This represents a potential step change in the cost to generate hydrogen at small volumes. Typically, plants in the size range 20 times larger than the $4.8 \mathrm{~kg} / \mathrm{h}$ design would be required to achieve similar unit hydrogen costs. As a result, the potential exists for a cost competitive new benchmark for on-site hydrogen generation using existing SMR and related technologies at product flowrates of $4.8 \mathrm{~kg} / \mathrm{h}$.

After completing this analysis, the next step involved scaling the cost to cover the range specified in the DOE program of 2.4 to $12 \mathrm{~kg} / \mathrm{h}$ of hydrogen production. To simplify the graphs, the average of the DMI and BDI estimates, developed for the alpha concepts, were used as the baseline. Established scale factors were then individually applied to all of the system components. The overall skid design remains a single skid for production levels up to $12 \mathrm{~kg} / \mathrm{h}$ hydrogen. Figures 10 and 11 show product costs for various cases and the impact of utilities on the overall product hydrogen cost. 
Cost Comparison vs Units Produced and Flowrate of Hydrogen Product

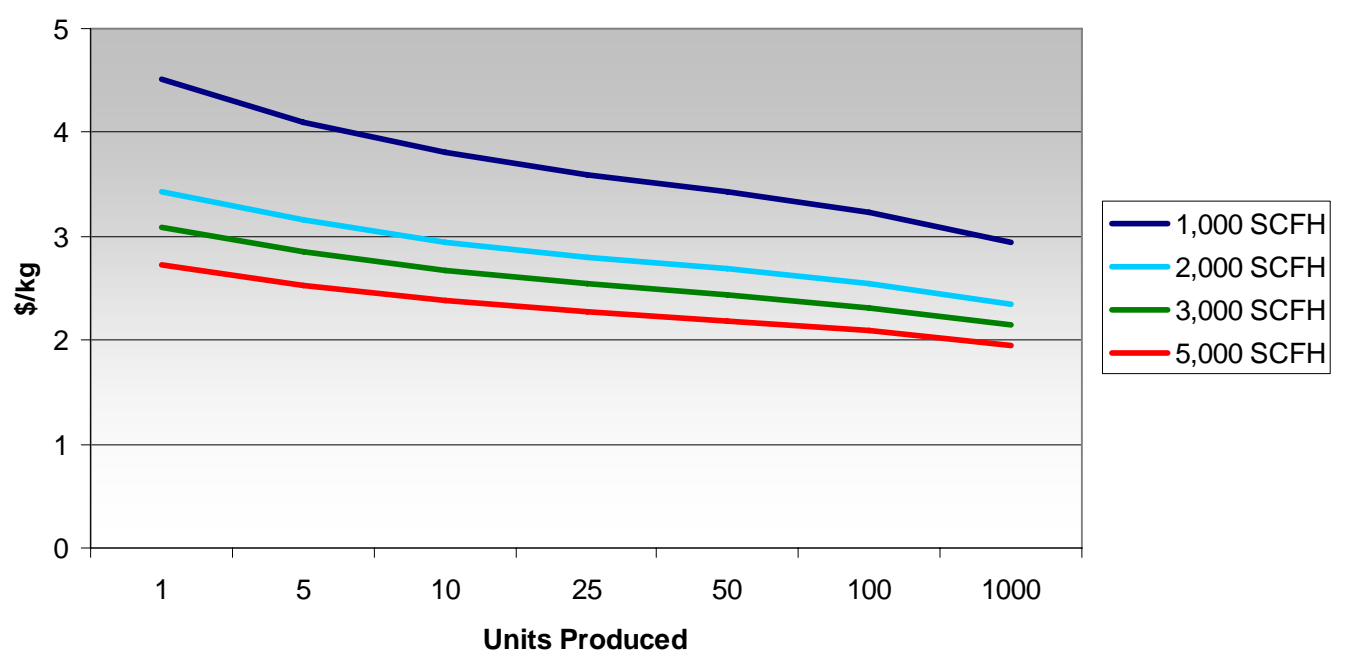

Figure 10. Unit hydrogen cost versus units produced and system capacity.

\section{System Cost Comparison vs Units Produced (Utilities \& Installed Cap/Op Costs (Capital, M\&R, Contingency \& ROI))}

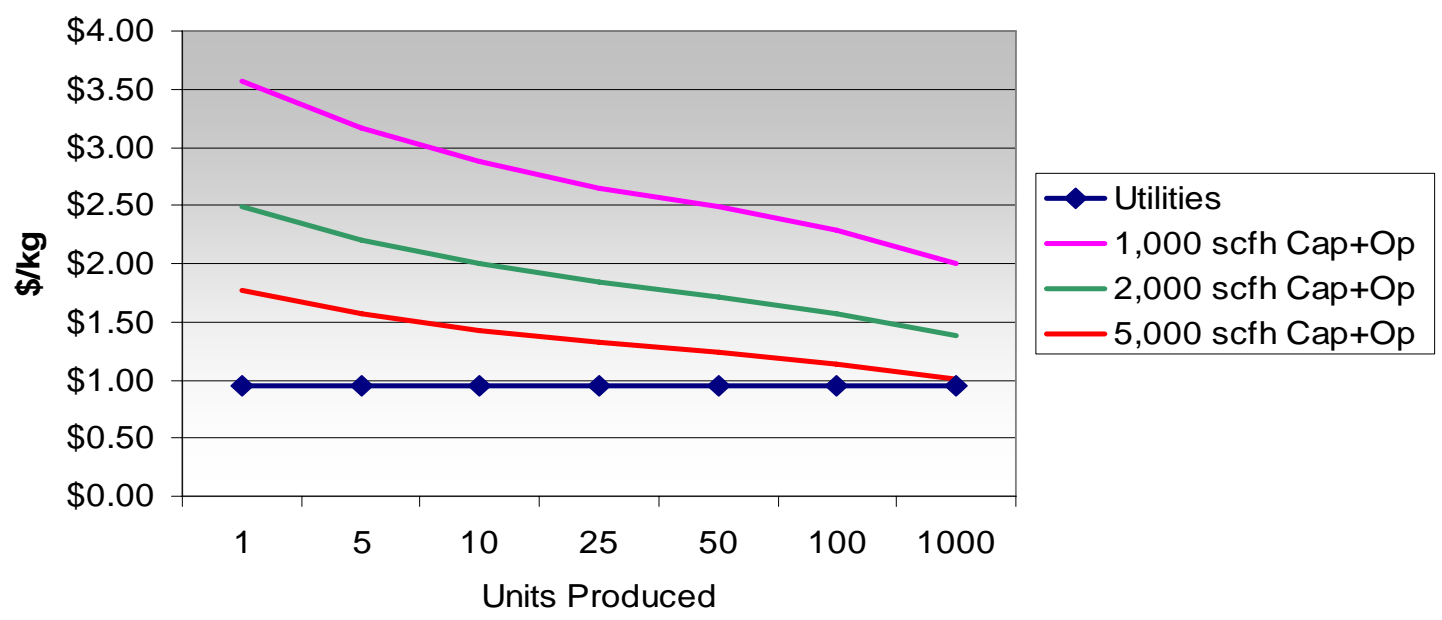

Figure 11. Unit project and utility costs versus units produced and system capacity.

\section{4 - Market and Business Profitability Analysis}

Figure 10 shows the cost of hydrogen from the low cost hydrogen production platform ranges from $\sim \$ 2.00-\$ 4.60$ per $\mathrm{kg}$ depending on size and number of units produced. These estimates do not include compression, storage, and dispensing. Phase III of the program included tasks for compression and dispensing as part of the integration of the prototype in a fueling station.

DOE Record 5013 (http://www.hydrogen.energy.gov/pdfs/5013 h2 cost goal.pdf) established a hydrogen cost goal of \$2.00-\$3.00 per gge (gallon gasoline equivalent). Although not explicitly stated, it is probable that this cost goal includes compression, storage, and dispensing necessary to deliver the hydrogen to the vehicle. Assuming that compression, storage, and 
dispensing account for $25 \%$ of the total cost, the hydrogen production cost target for an on-site system would be $\$ 1.50$ to $\$ 2.25$ per gge or $\mathrm{kg}$. As shown in figure 10 , with these cost targets, units as small as about $4.8 \mathrm{~kg} / \mathrm{h}$ (2000 scfh), produced in quantity, can meet or surpass the upper bound of the DOE cost goal, which is based on a projected gasoline price of $\$ 1.29 / \mathrm{gallon}$ in 2015. If one assumes a higher gasoline price, the hydrogen target would be raised by the same percentage.

The cost of hydrogen obtained from the LCHPP is projected to be lower than the price of liquid hydrogen or hydrogen produced by electrolysis even at the $4.8 \mathrm{~kg} / \mathrm{h}$ production volume and limited manufacturing quantities. The liquid hydrogen price is between $\$ 1.15$ and $\$ 1.80$ per 100 scf (\$4.77 and \$7.47 per kg) (Chemical Market Reporter, February 24, 2003, p. 43). The projected hydrogen cost from mass produced electrolysis equipment (Thomas 1997) using power costs assumed in this study result in the cost of hydrogen produced by electrolysis to be $\$ 3.40$ per $\mathrm{kg}$ for a $12 \mathrm{~kg} / \mathrm{h}$ plant. Neither liquid hydrogen nor electrolysis is likely to meet even the upper bound of the DOE cost goal.

\subsubsection{Market Size Assessment}

\section{Transportation Sector - Passenger Vehicles:}

The estimation for passenger cars powered by fuel cells is based on a modification of the CARB mandate on their web site and possible amendments to the ZEV program. A baseline projection (based on CARB mandate) was developed assuming gradual growth of the fuel cell market. Table 4 describes assumptions made for passenger cars. Figure 12 shows market projections for fuel cell cars in the U.S. The baseline projection for $\mathrm{H}_{2}$-fueled fuel cell cars shows that the rate of production of these cars will be $\sim 8,000$ in 2010, and $\sim 200,000$ in 2020.

\begin{tabular}{|l|l|}
\hline Table 4. Assumptions for Fuel Cell Cars Market (2003) \\
\hline No. of cars sold in California in 2003 & $1.5 \mathrm{MM}$ \\
\hline Percentage share of large/intermediate volume manufacturer & $65 \%$ \\
\hline Annual car sales growth & $1.5 \%$ \\
\hline $\begin{array}{l}\text { Average } \mathrm{H}_{2} \text { consumption by car (this implies } 12000 \text { miles driven/yr } \\
\text { and } 75 \text { mpgge efficiency (LHV) or } 5.6 \text { scf } \mathrm{H}_{2} / \text { mile) }\end{array}$ & $1 \mathrm{~kg} / \mathrm{h}$ \\
\hline Market Parameters for Fuel Cell Cars: & \\
\hline FCVs as \% of cars sold by large/intermediate manufacturer in 2010 & $0.05 \%$ \\
\hline FCVs as \% of cars sold by large/intermediate manufacturer in 2020 & $1.0 \%$ \\
\hline Ratio of new $\mathrm{H}_{2}$ FCVs in US/California in 2010 & 1 \\
\hline Ratio of new $\mathrm{H}_{2}$ FCVs in US/California in 2020 & 4.0 \\
\hline
\end{tabular}




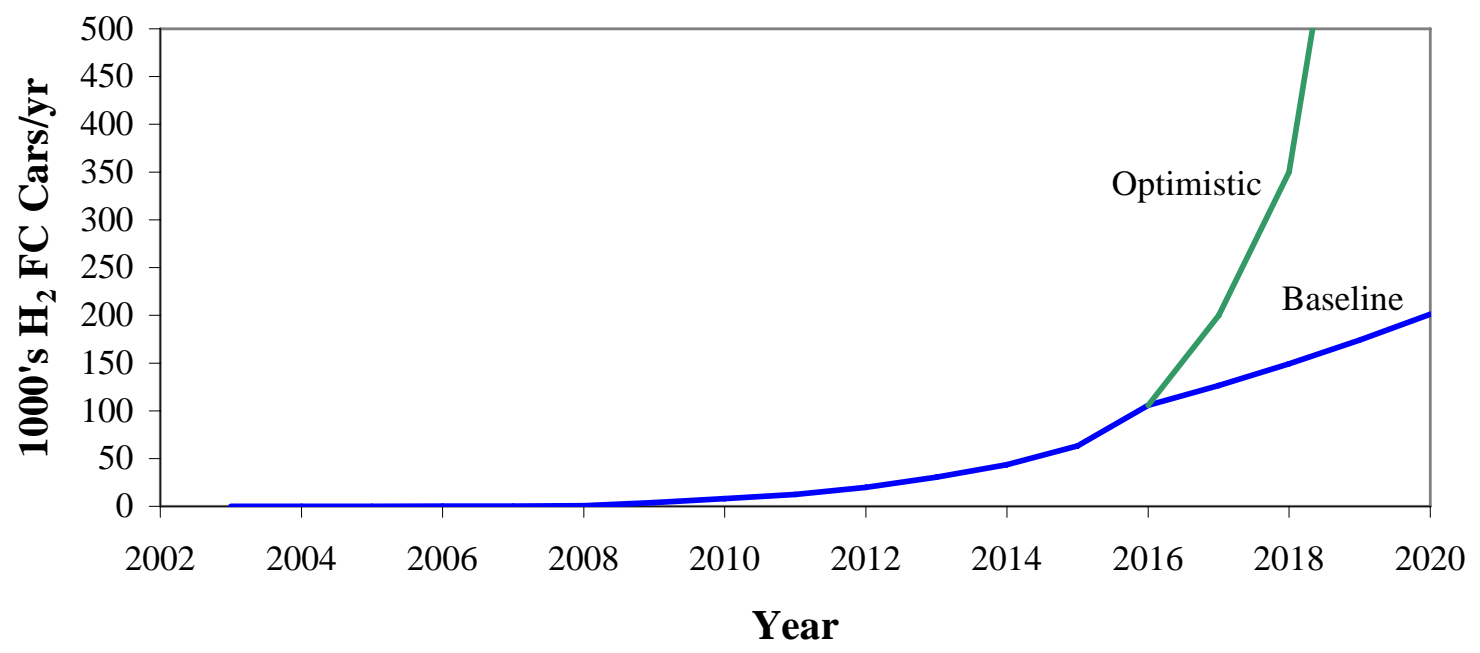

Figure 12. Projections for Hydrogen-Fueled Fuel Cell Cars in the U.S (2003).

Many barriers still exist to the development of the $\mathrm{H}_{2}$ fuel cell vehicle market. These include: 1) infrastructure associated with cost effective hydrogen fueling stations; 2 ) on-board hydrogen storage; 3 ) the cost of fuel cells for vehicles; 4) Minimal wells to wheels energy saving associated with the use of FCV as compared to hybrid ICEVs. Below are a few observations regarding the barriers.

1. The fuel-related obstacles can be overcome to some extent by tax breaks to hydrogen so as to facilitate introduction of $\mathrm{H}_{2} \mathrm{FCVs}$.

2. The recent progress made by Quantum and others on developing high-pressure tanks for on-board storage has raised the hope for cost-effective storage.

3. The cost of the fuel cell does remain a major obstacle. A mid-size fuel cell car will need a $75 \mathrm{~kW}$ fuel cell stack. At the current cost of $\$ 5,000 / \mathrm{kW}$, the fuel cell engine alone will cost $\$ 375,000$. It is not clear when the fuel cell cost can be reduced to the $\$ 30 / \mathrm{kW}$ level that is necessary to compete with IC engine.

4. Continued development of the hybrid ICEV vehicle shows promise in improving overall vehicle efficiency numbers.

Transportation Sector - Bus fleets

For fuel cell buses, a forecast for California was developed based on the CARB mandate and the projections for the entire US was made on the same basis as that for fuel cell cars. These projections are shown in figure 13. 


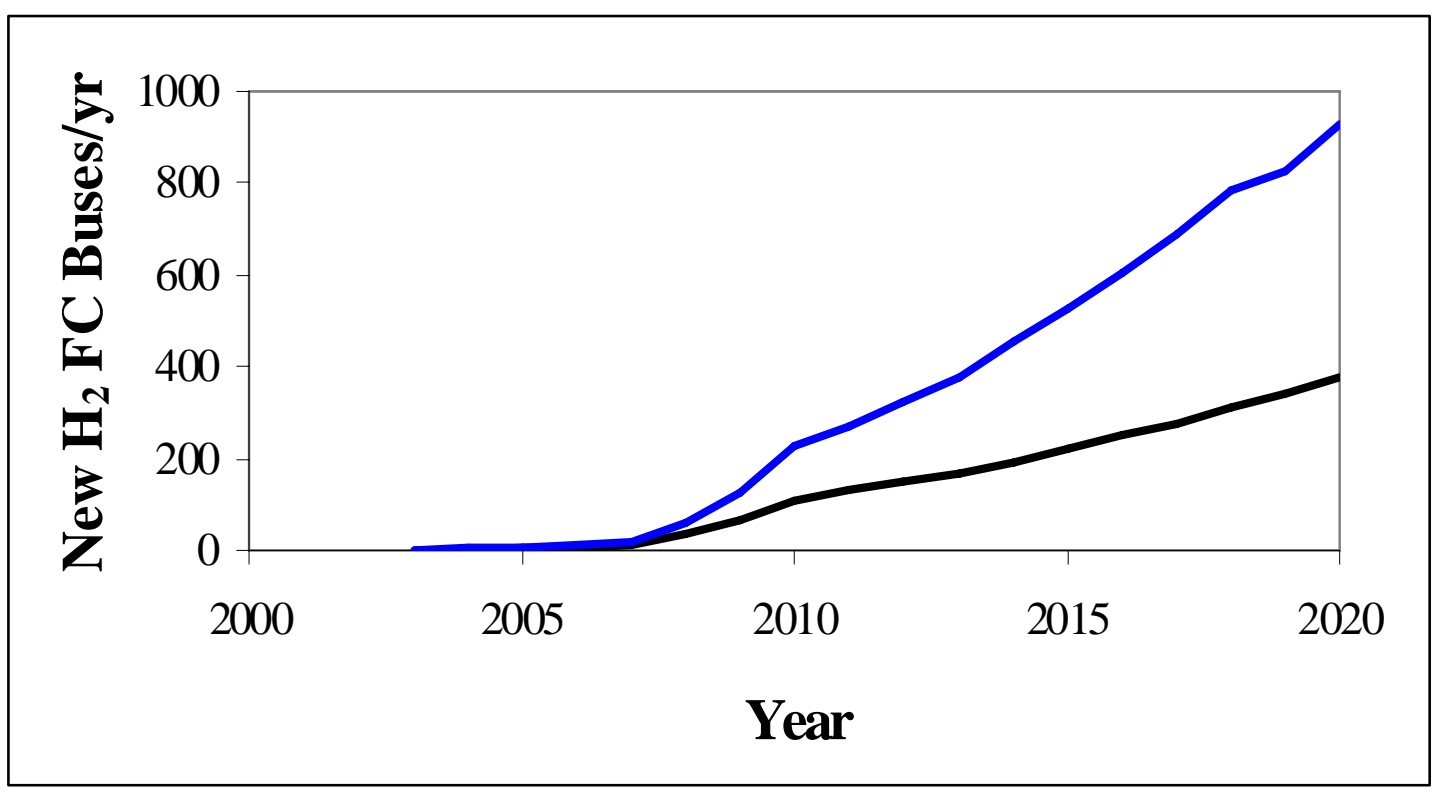

Figure 13. Projections for Hydrogen Fueled Fuel Cell Buses in the U.S.

\subsubsection{Summary of Market Opportunities}

The $12 \mathrm{~kg} / \mathrm{h}$ plant is the lowest unit cost option hydrogen, but utilization issues associated with the $12 \mathrm{~kg} / \mathrm{h}$ plants will limit their application, therefore total market requirements have been based upon the use of a $4.8 \mathrm{~kg} / \mathrm{h}$ plant.

It is expected that several suppliers will compete for market share. Therefore, totals presented within the table are based upon a 25\% market share for any given supplier. Figure 14 shows the total number of plants any given supplier is expected to produce. The light blue line shows the number of plants based upon the optimistic projection, and the dark blue line shows the conservative estimate.

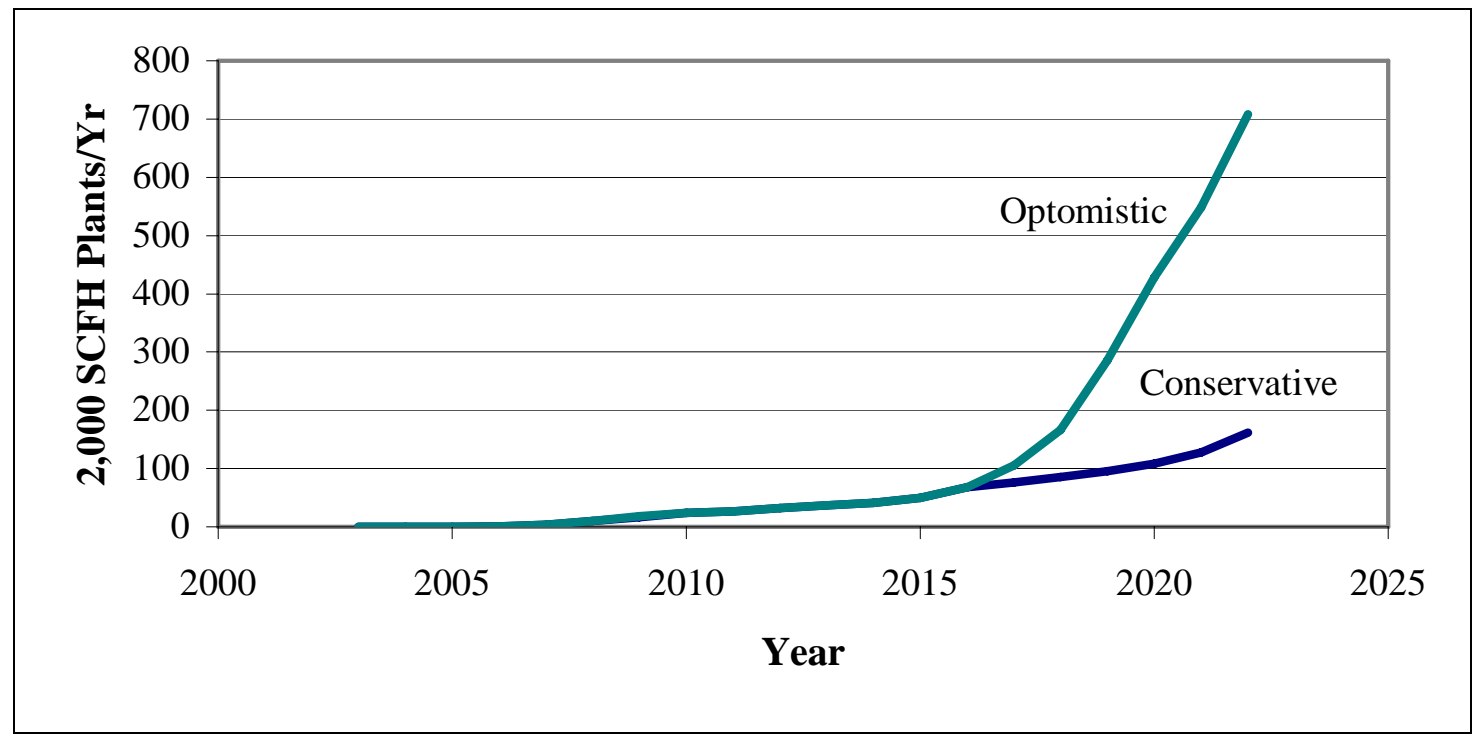

Figure 14. Total number of $4.8 \mathrm{~kg} / \mathrm{h}$ Plants - Optimistic and Conservative Scenarios (2003).

As discussed in previous sections, many barriers still exist to the development of the $\mathrm{H}_{2}$ fuel cell vehicle market. In view of this, it is recommended that total volumes be based upon the 
conservative estimates for these market segments. The total number of $4.8-12 \mathrm{~kg} / \mathrm{h}$ in 2010 plants would be about 30, and these numbers grow to about 125 in year 2020.

\subsection{Phase II - Component Testing and Modeling}

The Phase I design and economic feasibility analysis indicated that the potential exists for a significant reduction in the cost to produce hydrogen with a small on-site SMR based system. Even though the economics of the preferred approach showed a step change in the unit cost of small on-site hydrogen, a significant effort was required to fully understand the critical components and the overall system prior to introducing a commercially available unit. The main focus of Phase II was to serve as proof-of-concept for the Phase I design. This proof of concept was accomplished through both detailed engineering/modeling and component testing. Phase II also had tasks related to detail design, tooling design and continued economic/business analysis. The primary goal of Phase II was to address all potential system issues and be ready to confidently build a Phase III system that would meet the overall program goals including a safe, economical, maintainable and reliable system for the production of hydrogen for the transportation and industrial markets.

Praxair, in Phase I, showed that significant improvements in cost, plant layout, system integration and overall system optimization were achievable. Phase II of the program focused on demonstrating both the design and economic viability of the concept developed in Phase I through detailed component analysis and testing.

\section{Approach}

The initial effort in Phase II was to complete the detail design of the Phase I concept and related auxiliary components. This information was then used to generate heat transfer and reaction kinetic models as well as the stress and thermal engineering models of the system. A test plan and component test apparatus for the testing of key components was also developed from the detailed design. A large portion of the program was associated with component testing and converging the prototype tests with the reactor and system computer models to define the optimum system design and the operating parameters.

At the conclusion of Phase II, a detailed design was completed and evaluated through computer modeling and component testing. The economic models were updated to reflect any system additions or subtractions. After successful design and economic development in Phase II, Phase III was submitted to the DOE with the goal of building and testing a prototype I demonstration unit as well as developing any tooling or infrastructure required for producing the system in the quantities required to meet the market demand.

\section{1 - Detail Design}

The part and assembly detail drawings of all components were updated and re-quoted in Phase II. The baseline design is a $4.8 \mathrm{~kg} / \mathrm{hr}$ single skid hydrogen system as depicted in figures 15 through 17 below. The overall system is designed to fit in a parking space at a typical fueling station and is designed for all domestic US climate conditions. The baseline system does not include compression and dispensing. A US patent has been awarded for the steam generation, reformer, shift, desulfurization and heat transfer integrated component design. 


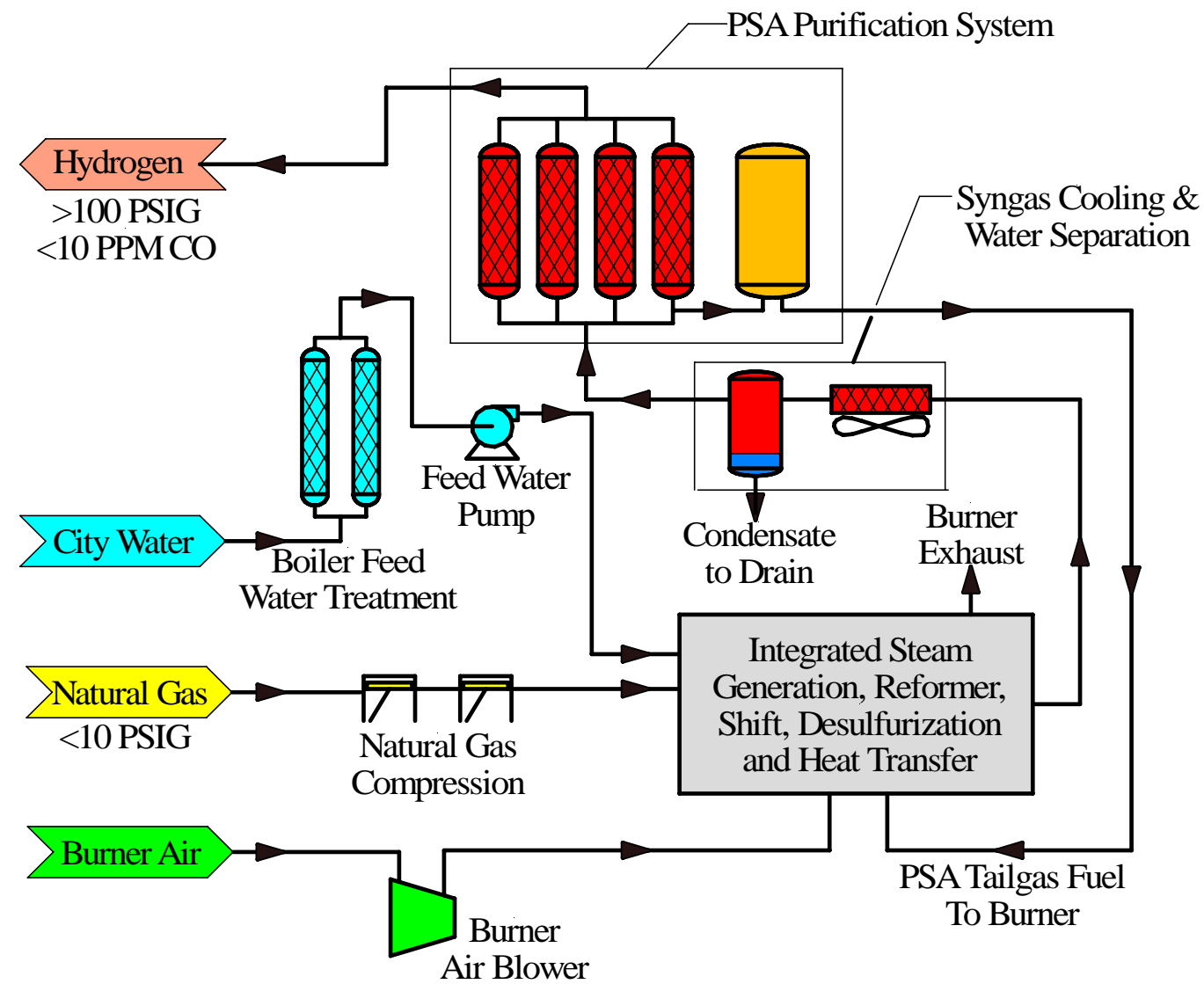

Figure 15. Process flow diagram for the LCHPP system. 

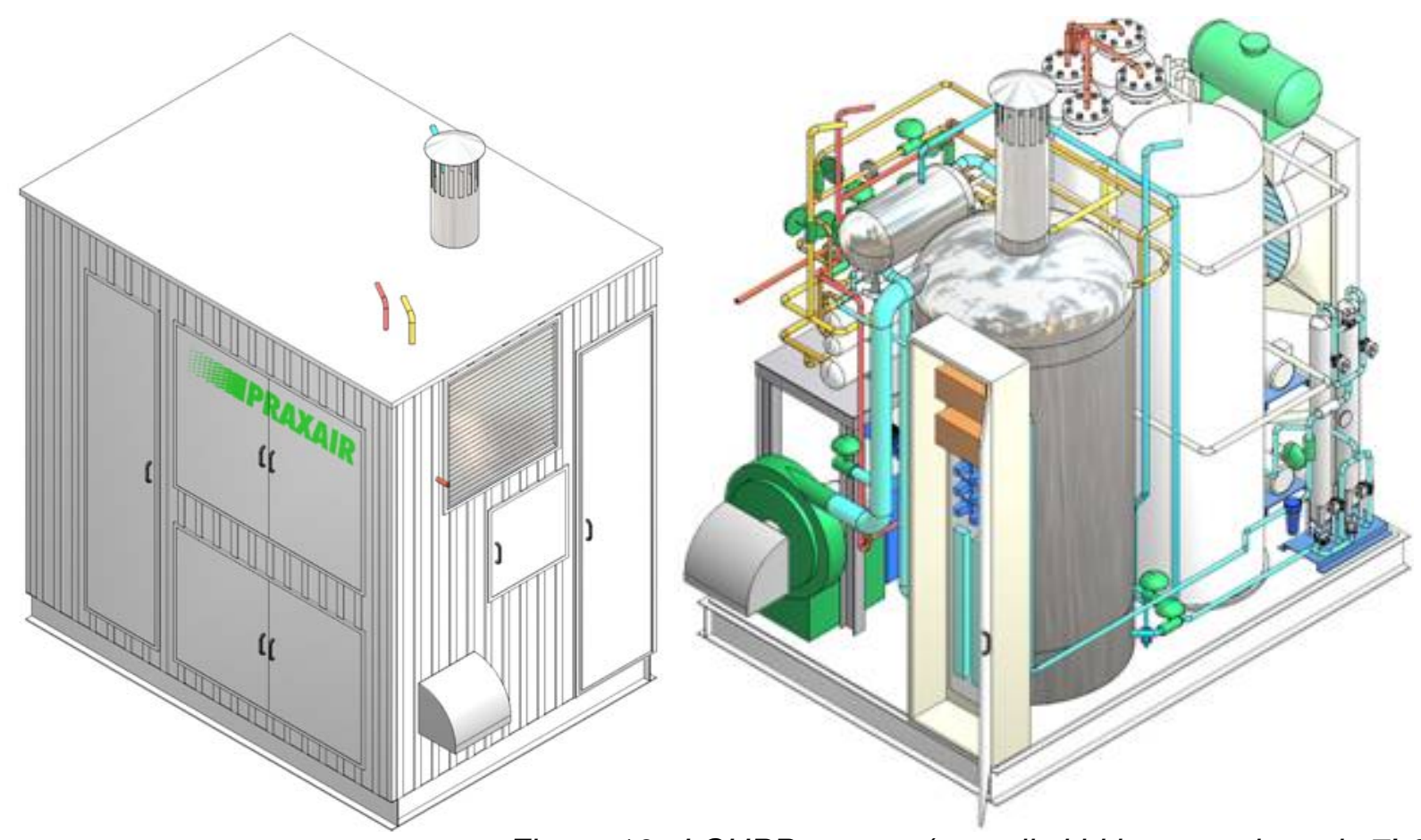

Figure 16. LCHPP system (overall skid is approximately 7'-6" $x$ 10' x 10')

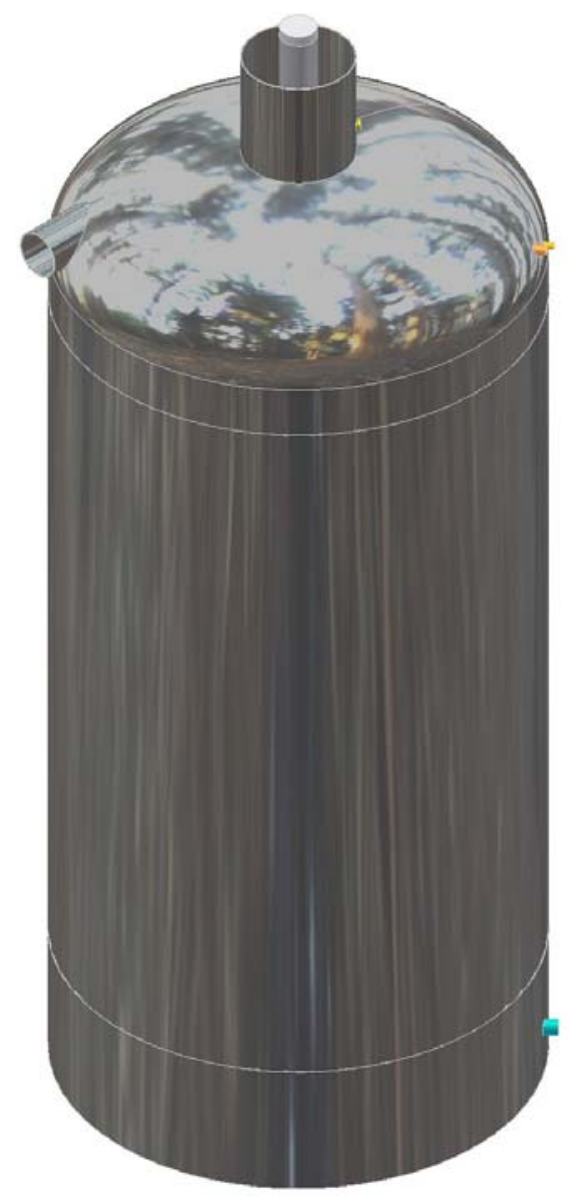

Figure 17. Integrated high temperature component.

The integrated high temperature component contains all of the high temperature operations that are typically accomplished in separate components in a traditional SMR plant. By integrating all of the high temperature operations into a single component, the mass of the system is greatly reduced, the efficiency is increased and overall cost of the unit is significantly reduced. Applying the DFMA methodology to the compact integrated design has resulted in an additional cost reduction. The high level of integration does however present a problem for maintenance access to the individual components/subsystems. To address this concern, a critical goal of the Phase II testing was to demonstrate the reliability of these internal components to assure that the Phase III and future production systems will meet the overall reliability and maintenance goals.

\section{2 - Computer Modeling}

The computer modeling tasks included the development of process flow models of the system. Detailed CFD models of the heat transfer, process stream compositions and the overall flow characteristics were developed. These models were verified and updated using the test results from the various test apparatuses. 


\section{3 - Component Development \& Testing}

The main focus of Phase II was the component testing. Two separate test apparatuses were constructed and operated.

\subsubsection{Bench Scale Catalyst Testing}

A laboratory scale reactor was designed to verify the feasibility of the reformer catalyst containment and to evaluate the key parameters related to catalyst containment. This reactor, shown below in figure 18, is a scaled reformer tester that allows for precise control and testing of the feed gases and configuration of the reformer component. The test apparatus includes a furnace, steam generation system, analysis equipment and related control components. The gases supplied to this test system include steam, methane, hydrogen, carbon monoxide, carbon dioxide, and nitrogen.

Steam-methane reforming experiments were conducted utilizing a commercial catalyst. The catalyst has an engineered shape similar to that of a honeycomb. The catalyst particles are approximately $13.5 \mathrm{~mm}$ in length and $10.5 \mathrm{~mm}$ in diameter. The catalyst was studied over a range of feed rates, catalyst exit temperatures and reactor pressures. The data are summarized in figures 19 and 20.

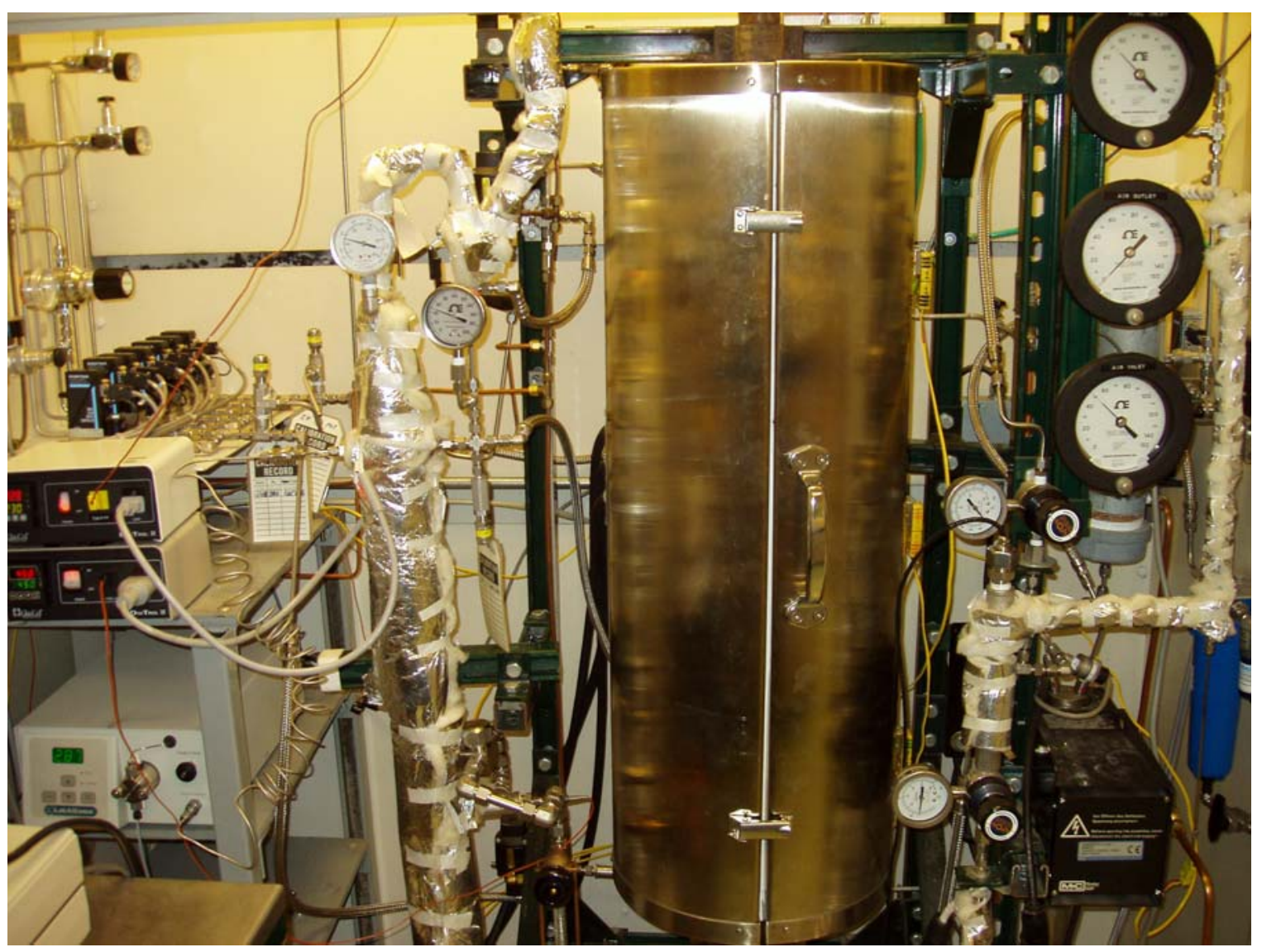

Figure 18. Photo of laboratory scale test apparatus

The feed to the reactor contained a fixed composition of $18.2 \%$ methane, $18.2 \%$ nitrogen, and $63.6 \%$ steam (3.5:1 steam to carbon). Nitrogen was added to the feed to serve as an internal standard for use in mass balance assessments. Gas hourly space velocities (GHSV) ranging from $1650 \mathrm{hr}^{-1}$ to $9900 \mathrm{hr}^{-1}$ were investigated. The full scale design gas hourly space velocity for 
the reformer component is approximately $1414 \mathrm{hr}^{-1}$, and therefore, this study examined catalyst performance at throughputs well exceeding the design case. Reactor pressures of 50-125 psig were investigated in accordance with the full scale design pressure of 123 psig. Figure 22 shows methane conversion data as a function of feed rate at different catalyst exit temperatures at a reactor pressure of 125 psig. As expected, the methane conversion increases with increasing exit temperatures and decreasing feed rates. As indicated by the data, the catalyst performance is sufficient to achieve methane conversions well in excess of $90 \%$ at a full scale design exit temperature of $1600 \mathrm{~F}$.

Another method of examining catalyst performance is to measure how close the catalyst gets to achieving an equilibrium product stream composition. The equilibrium approach $\Delta T$ is used to quantify this, and is defined as the difference between the measured exit temperature and the temperature required to achieve the measured conversion at equilibrium. It is desirable to have the approach $\Delta \mathrm{T}$ be as closed to 0 as possible. Figure 20 shows how the approach to equilibrium varies for different feed rates and exit temperatures at a reactor pressure of 125 psig. As expected, the approach to equilibrium decreases and the feed rate decreases. It is clear that the catalyst produces equilibrium approach $\Delta T$ 's of less than $20 \mathrm{~F}$ at full scale design conditions, regardless of exit temperature.

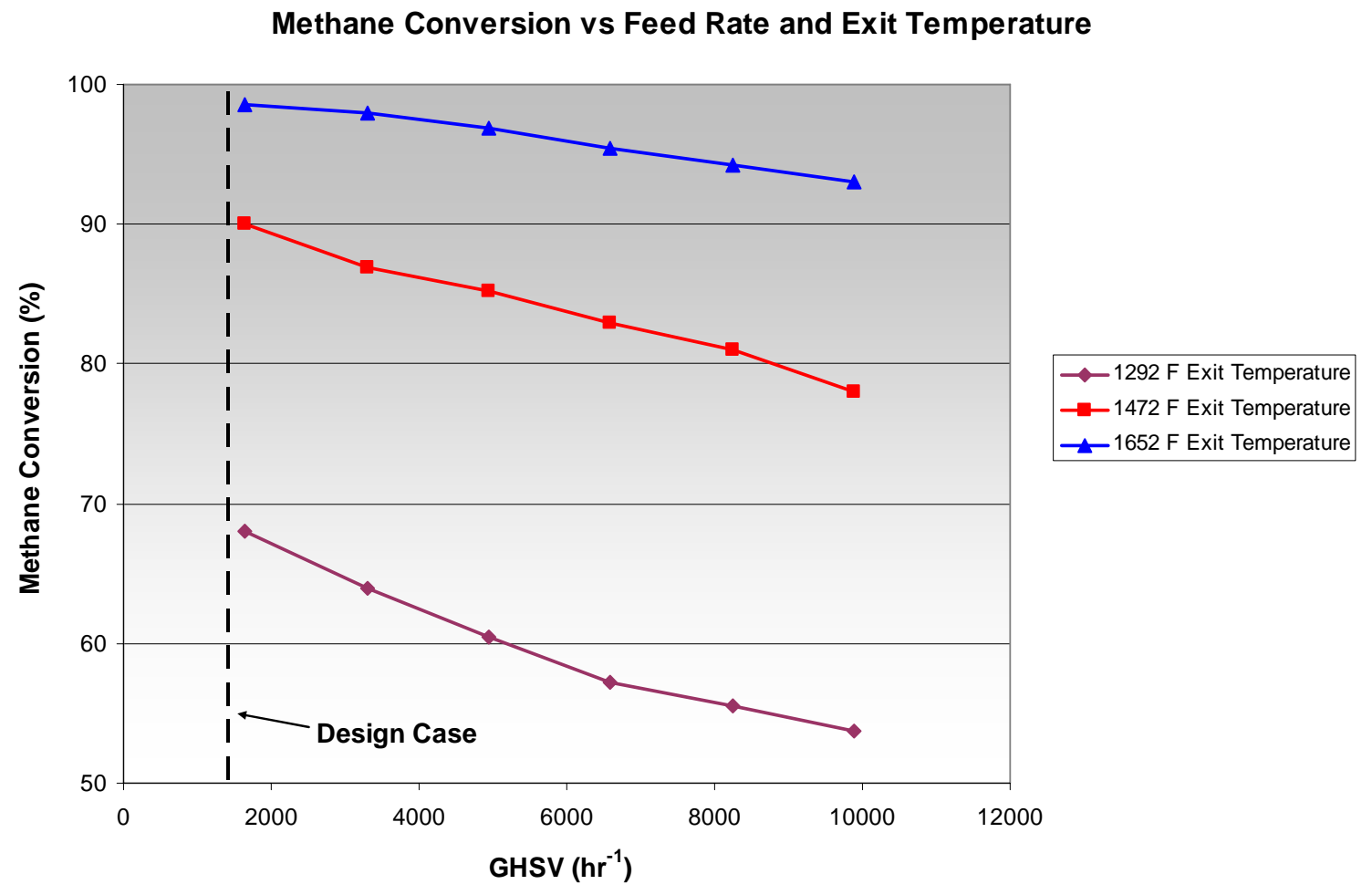

Figure 19. Methane conversion as a function of feed rate and exit temperature at 125 psig. 


\section{Equilibrium Approach $\Delta \mathrm{T}$ vs Feed Rate and Exit Temperature}

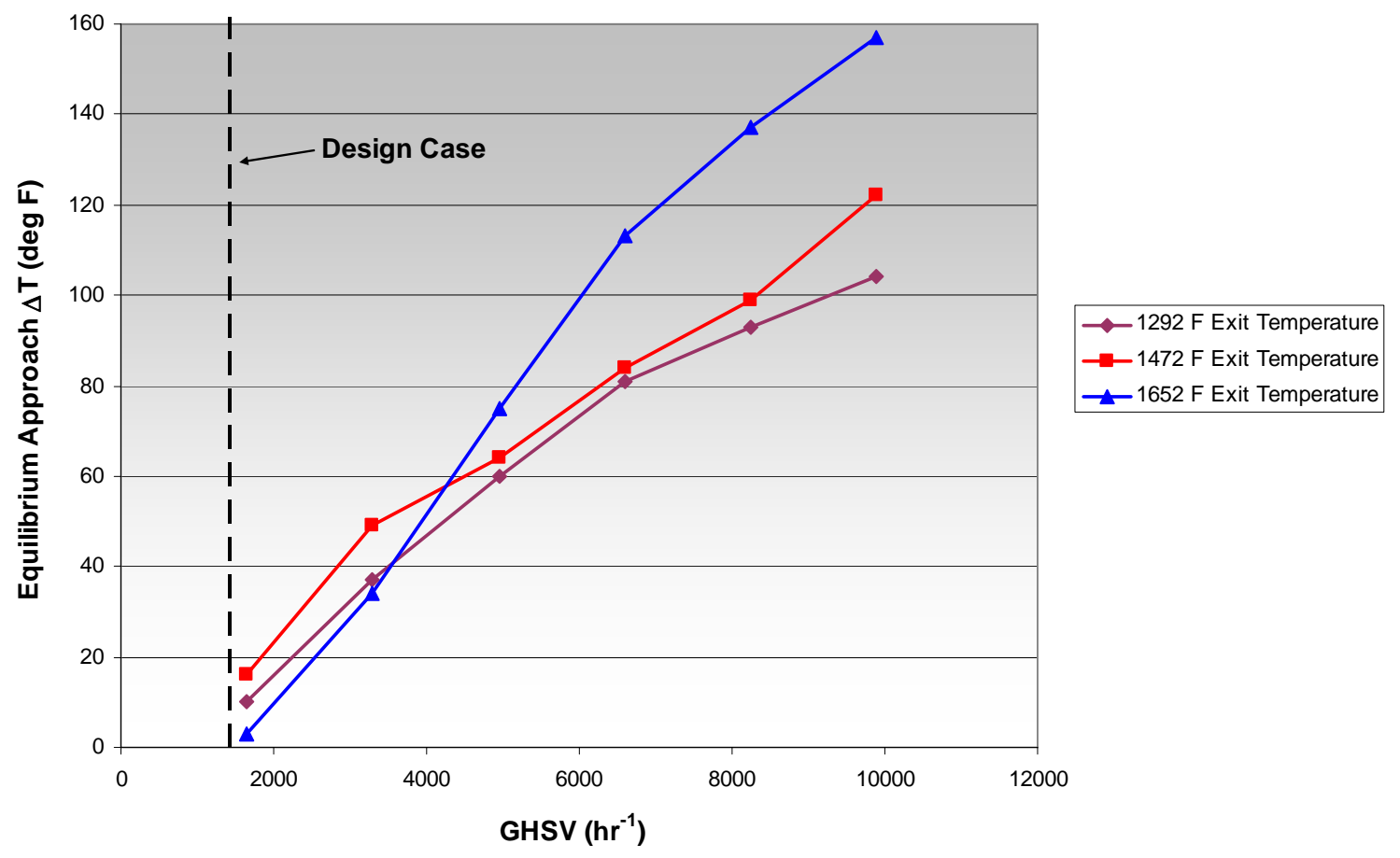

Figure 20. Equilibrium approach $\Delta T$ as a function of feed rate and exit temperature at 125 psig.

Additional experiments were conducted to understand the effect of nitrogen dilution on the data presented above. A series of tests were conducted for a feed containing a 3.5:1 ratio of steam to methane without any nitrogen present. Table 5 shows a comparison of the measured methane conversions for equivalent feed streams with and without nitrogen present. Here, equivalent means that the total flow of methane + steam is the same for the two feed streams. Therefore, the space velocity of the nitrogen containing stream is actually higher than that of the stream without nitrogen (3300 hr ${ }^{-1}$ vs $2700 \mathrm{hr}^{-1}$ ). 
Table 5. Methane conversion data with and without the presence of nitrogen in the feed.

\begin{tabular}{|c|c|c|c|c|c|}
\hline \multicolumn{6}{|l|}{50 psig Reactor Pressure } \\
\hline \multicolumn{3}{|l|}{ W/ $\mathrm{N}_{2}$ Dilution } & \multicolumn{3}{|l|}{ w/o $\mathrm{N}_{2}$ Dilution } \\
\hline \begin{tabular}{|l|} 
Exit Temperature (deg F) \\
\end{tabular} & $\mathrm{CH}_{4}$ Conversion (\%) & Equilibrium Approach $\Delta \mathrm{T}(\mathrm{deg} \mathrm{F})$ & Exit Temperature (deg F) & $\mathrm{CH}_{4}$ Conversion (\%) & Equilibrium Approach $\Delta \mathrm{T}(\mathrm{deg} \mathrm{F})$ \\
\hline 1292 & 78.1 & 45 & 1292 & 73.2 & 58 \\
\hline 1472 & 95.3 & 58 & 1472 & 95.1 & 40 \\
\hline 1652 & 99.3 & 72 & 1652 & 99.3 & 45 \\
\hline \multicolumn{6}{|l|}{75 psig Reactor Pressure } \\
\hline \multicolumn{3}{|l|}{ w/ $\mathrm{N}_{2}$ Dilution } & \multicolumn{3}{|l|}{ w/o $\mathrm{N}_{2}$ Dilution } \\
\hline \begin{tabular}{|l|} 
Exit Temperature (deg F) \\
\end{tabular} & $\mathrm{CH}_{4}$ Conversion (\%) & Equilibrium Approach $\Delta \mathrm{T}$ (deg F) & Exit Temperature (deg F) & $\mathrm{CH}_{4}$ Conversion (\%) & Equilibrium Approach $\Delta \mathrm{T}$ (deg F) \\
\hline 1292 & 73.2 & 35 & 1292 & 67.8 & 49 \\
\hline 1472 & 94.5 & 23 & 1472 & 91.6 & 43 \\
\hline 1652 & 98.8 & 63 & 1652 & 98.8 & 36 \\
\hline \multicolumn{6}{|l|}{100 psig Reactor Pressure } \\
\hline \multicolumn{3}{|l|}{ w/ $\mathrm{N}_{2}$ Dilution } & \multicolumn{3}{|l|}{ w/o $\mathrm{N}_{2}$ Dilution } \\
\hline \begin{tabular}{|l|} 
Exit Temperature (deg F) \\
\end{tabular} & $\mathrm{CH}_{4}$ Conversion (\%) & Equilibrium Approach $\Delta \mathrm{T}$ (deg F) & Exit Temperature (deg F) & $\mathrm{CH}_{4}$ Conversion (\%) & Equilibrium Approach $\Delta \mathrm{T}$ (deg F) \\
\hline 1292 & 67.7 & 38 & 1292 & 66.5 & 25 \\
\hline 1472 & 91.0 & 35 & 1472 & 89.5 & 31 \\
\hline 1652 & 98.7 & 27 & 1652 & 98.2 & 32 \\
\hline \multicolumn{6}{|l|}{125 psig Reactor Pressure } \\
\hline \multicolumn{3}{|l|}{$\mathrm{w} / \mathrm{N}_{2}$ Dilution } & \multicolumn{3}{|l|}{ w/o $\mathrm{N}_{2}$ Dilution } \\
\hline \begin{tabular}{|l|} 
Exit Temperature (deg F) \\
\end{tabular} & $\mathrm{CH}_{4}$ Conversion (\%) & Equilibrium Approach $\Delta \mathrm{T}$ (deg F) & Exit Temperature (deg F) & $\mathrm{CH}_{4}$ Conversion (\%) & Equilibrium Approach $\Delta \mathrm{T}$ (deg F) \\
\hline 1292 & 63.9 & 37 & 1292 & 66.2 & 1 \\
\hline 1472 & 86.9 & 49 & 1472 & 85.5 & 40 \\
\hline 1652 & 98.0 & 34 & 1652 & 97.3 & 36 \\
\hline
\end{tabular}

It is apparent that nitrogen dilution has only a small effect on measured methane conversion. The relative performance of the two sets of data is a function of both the difference in space velocity mentioned previously, as well as the higher partial pressure of the feed components (methane + steam) afforded without nitrogen dilution at the same total pressure. Because the methane reforming reaction involves a molar expansion, it becomes less favorable at higher reactant partial pressures. The equilibrium approach $\Delta T$ 's were also comparable for the two data sets, with the nitrogen dilution cases yielding values of $37 \mathrm{~F}, 49 \mathrm{~F}$ and $34 \mathrm{~F}$ for exit temperatures of $1292 \mathrm{~F}, 1432 \mathrm{~F}$, and $1652 \mathrm{~F}$ versus values of $1 \mathrm{~F}, 40 \mathrm{~F}$, and $36 \mathrm{~F}$ for the cases without nitrogen dilution.

In terms of the full scale design, this data set shows that the catalyst is capable of achieving approximately $95 \%$ methane conversion at a space velocity that is nearly double the design space velocity at an exit temperature of $1600 \mathrm{~F}$ and a reactor pressure of $125 \mathrm{psig.}$

The test system described above was also utilized to investigate the performance of a commercial water-gas shift catalyst. The catalyst consists of cylindrical particles $4.9 \mathrm{~mm}$ in length and $8.5 \mathrm{~mm}$ in diameter. The catalyst was studied over a range of feed rates, catalyst exit temperatures and reactor pressures. The data are summarized in figures 21 and 22.

The feed to the reactor contained a fixed composition of $27.25 \%$ water, $37.5 \%$ hydrogen, $1.25 \%$ methane, $7.75 \%$ carbon monoxide, $3.75 \%$ carbon dioxide, and $22.5 \%$ nitrogen. This composition was chosen based on an equilibrium reformer product stream at $1600 \mathrm{~F}$. Nitrogen was added to the feed to serve as an internal standard for use in mass balance assessments. Gas hourly space velocities ranging from $1200 \mathrm{hr}^{-1}$ to $3600 \mathrm{hr}^{-1}$ were investigated. The full scale design gas hourly space velocity for the shift reactor is approximately $1948 \mathrm{hr}^{-1}$, and therefore, this study examined catalyst performance at throughputs up to nearly double the design rate. Reactor pressures of 50-125 psig were studied in accordance with the full scale design pressure of 95 psig. Figure 21 shows $\mathrm{CO}$ conversion data as a function of catalyst exit temperature for different feed rates at a reactor pressure of $100 \mathrm{psig}$, as well as the CO 
conversion predicted by equilibrium. As indicated by the data, the catalyst performance is sufficient to achieve CO conversions of $75-80 \%$ at a full scale design exit temperature of $700 \mathrm{~F}$.

Figure 22 shows how the approach to equilibrium varies for different feed rates and exit temperatures at a reactor pressure of 100 psig. The approach to equilibrium decreases as the feed rate decreases and the exit temperature increases. The shift catalyst produces equilibrium approach $\Delta \mathrm{T}$ 's of less than $50-75 \mathrm{~F}$ at full scale design conditions.

\section{Co Conversion vs Feed Rate and Exit Temperature}

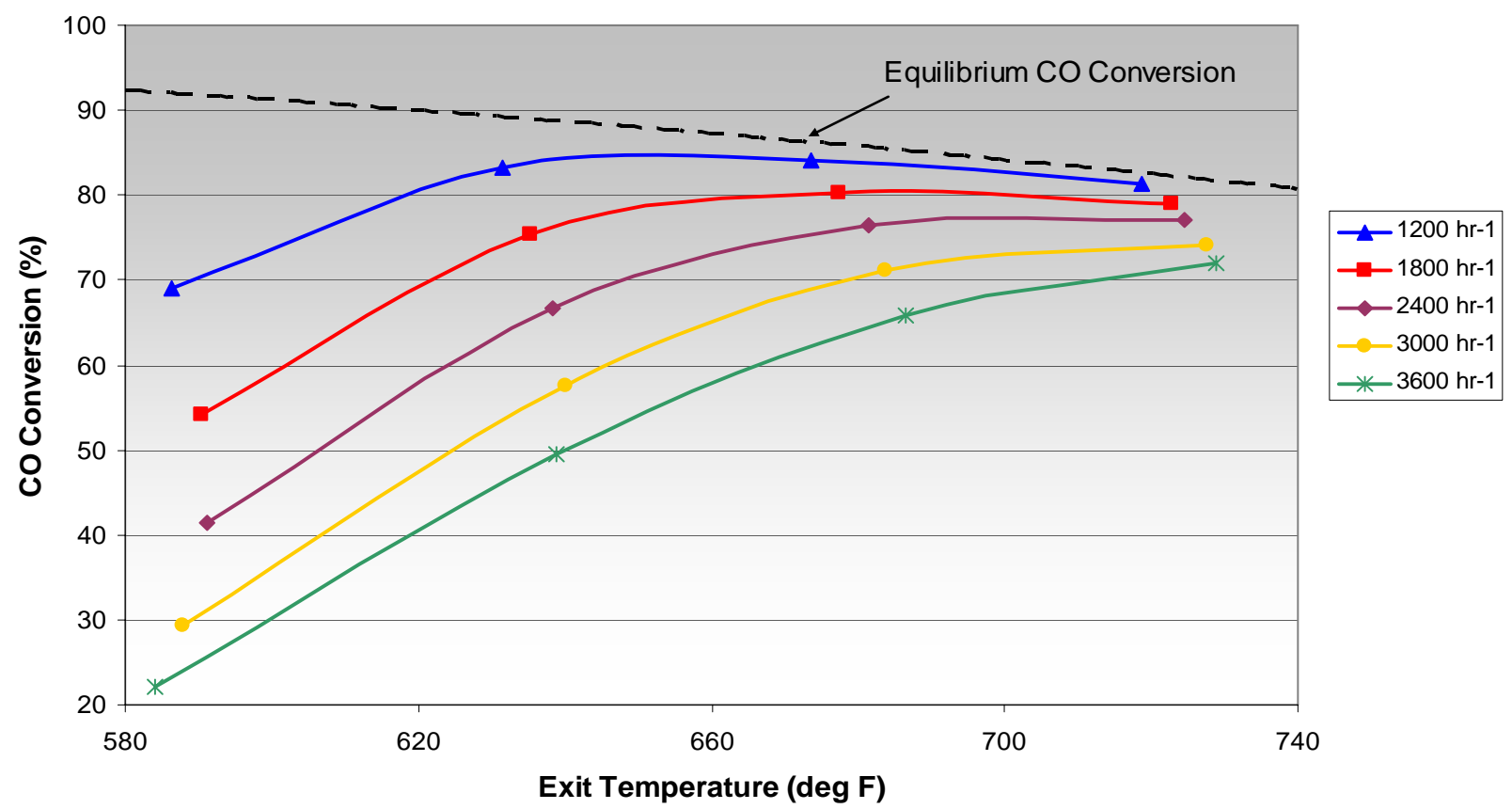

Figure 21. CO conversion as a function of feed rate and exit temperature at 100 psig. 


\section{Equilibrium Approach $\Delta \mathrm{T}$ vs Feed Rate and Exit Temperature}

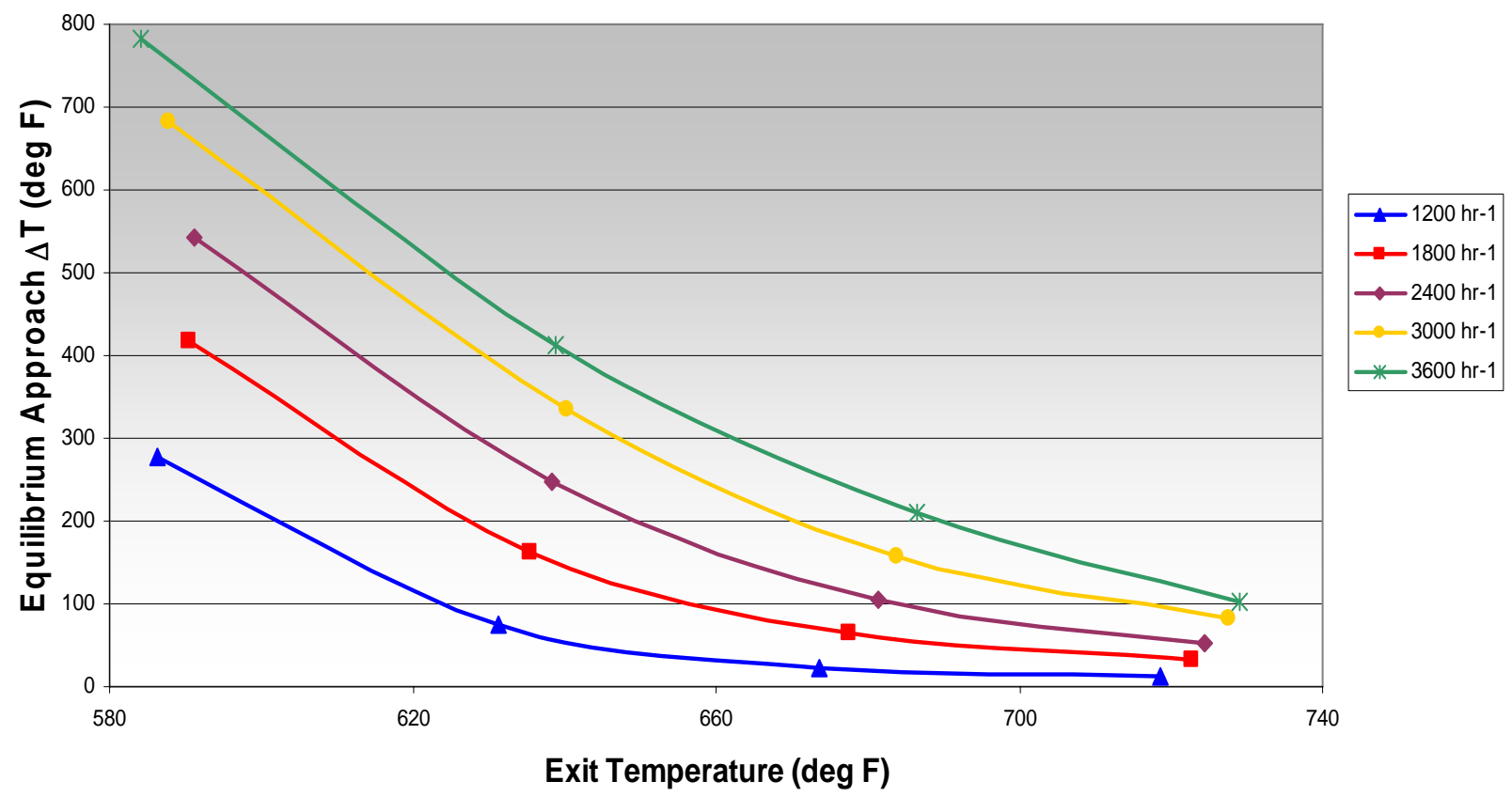

Figure 22. Equilibrium approach $\Delta T$ as a function of feed rate and exit temperature at 100 psig.

Additional experiments were conducted to understand the effect of nitrogen dilution on the data presented above. Table 6 shows a comparison of the measured $\mathrm{CO}$ conversions for equivalent feed streams with and without the presence of nitrogen. Here, equivalent means that the total flow of water + hydrogen + carbon monoxide + carbon dioxide + methane is the same for the two feed streams. Therefore, the space velocity of the nitrogen containing stream is actually higher than that of the stream without nitrogen (2400 hr-1 vs $1860 \mathrm{hr}^{-1}$ ). 
Table 6. CO conversion data with and without the presence of nitrogen in the feed.

\begin{tabular}{|c|c|c|c|c|c|}
\hline \multicolumn{6}{|l|}{50 psig Reactor Pressure } \\
\hline \multicolumn{3}{|l|}{ w/ $\mathrm{N}_{2}$ Dilution } & \multicolumn{3}{|l|}{ w/o $\mathrm{N}_{2}$ Dilution } \\
\hline \begin{tabular}{|l|} 
Exit Temperature (deg F) \\
\end{tabular} & CO Conversion (\%) & Equilibrium Approach $\Delta \mathrm{T}(\mathrm{deg} \mathrm{F})$ & Exit Temperature (deg F) & CO Conversion (\%) & Equilibrium Approach $\Delta \mathrm{T}(\mathrm{deg} \mathrm{F})$ \\
\hline 587.8 & 33.7 & 629 & 590.0 & 41.5 & 542 \\
\hline 638.1 & 59.9 & 315 & 637.6 & 66.0 & 256 \\
\hline 682.2 & 72.7 & 143 & 682.9 & 75.7 & 110 \\
\hline 726.1 & 75.2 & 73 & 725.1 & 76.3 & 61 \\
\hline \multicolumn{6}{|l|}{75 psig Reactor Pressure } \\
\hline \multicolumn{3}{|l|}{$\mathrm{w} / \mathrm{N}_{2}$ Dilution } & \multicolumn{3}{|l|}{ w/o $\mathrm{N}_{2}$ Dilution } \\
\hline \begin{tabular}{|l|} 
Exit Temperature (deg F) \\
\end{tabular} & CO Conversion (\%) & Equilibrium Approach $\Delta \mathrm{T}(\mathrm{deg} \mathrm{F})$ & Exit Temperature (deg F) & CO Conversion (\%) & Equilibrium Approach $\Delta \mathrm{T}(\mathrm{deg} \mathrm{F})$ \\
\hline 590.0 & 38.1 & 577 & 591.2 & 46.6 & 489 \\
\hline 637.2 & 63.6 & 280 & 638.1 & 70.6 & 210 \\
\hline 681.6 & 74.5 & 125 & 681.0 & 77.6 & 92 \\
\hline 724.6 & 76.7 & 58 & 724.9 & 77.3 & 51 \\
\hline \multicolumn{6}{|l|}{100 psig Reactor Pressure } \\
\hline \multicolumn{3}{|l|}{ w/ $\mathrm{N}_{2}$ Dilution } & \multicolumn{3}{|l|}{ w/o $\mathrm{N}_{2}$ Dilution } \\
\hline \begin{tabular}{|l|} 
Exit Temperature (deg F) \\
\end{tabular} & CO Conversion (\%) & Equilibrium Approach $\Delta \mathrm{T}$ (deg F) & Exit Temperature (deg F) & CO Conversion (\%) & Equilibrium Approach $\Delta \mathrm{T}(\operatorname{deg} \mathrm{F})$ \\
\hline 591.1 & 41.4 & 542 & 591.2 & 49.3 & 463 \\
\hline 638.2 & 66.7 & 248 & 637.3 & 72.7 & 189 \\
\hline 681.4 & 76.4 & 105 & 680.7 & 78.7 & 79 \\
\hline 724.5 & 77.2 & 53 & 724.0 & 77.6 & 49 \\
\hline \multicolumn{6}{|l|}{125 psig Reactor Pressure } \\
\hline \multicolumn{3}{|l|}{ w/ $\mathrm{N}_{2}$ Dilution } & \multicolumn{3}{|l|}{ w/o $\mathrm{N}_{2}$ Dilution } \\
\hline \begin{tabular}{|l|} 
Exit Temperature (deg F) \\
\end{tabular} & CO Conversion (\%) & Equilibrium Approach $\Delta \mathrm{T}$ (deg F) & Exit Temperature (deg F) & CO Conversion (\%) & Equilibrium Approach $\Delta \mathrm{T}(\mathrm{deg} \mathrm{F})$ \\
\hline 591.3 & 43.8 & 517 & 592.3 & 51.9 & 436 \\
\hline 637.2 & 68.3 & 233 & 638.5 & 74.8 & 165 \\
\hline 680.7 & 77.1 & 98 & 679.8 & 79.6 & 70 \\
\hline 724.5 & 77.0 & 55 & 723.9 & 78.1 & 43 \\
\hline
\end{tabular}

The removal of nitrogen from the feed stream increases the CO conversion relative to cases where nitrogen is present. This is due to the decrease in space velocity associated with the removal of nitrogen. In addition, the equilibrium approach $\Delta \mathrm{T}$ 's also decrease when nitrogen is removed. The effect of nitrogen dilution is most pronounced for lower exit temperatures, where conversions are low and approaches to equilibrium are high.

In terms of the full scale design, this data set shows that the catalyst is capable of achieving approximately $78 \% \mathrm{CO}$ conversion at a space velocity that is comparable to the design space velocity at an exit temperature of $700 \mathrm{~F}$ and a reactor pressure of 100 psig.

\subsubsection{Full Scale Component Testing}

In addition to the bench scale catalyst tester, a full scale component tester was constructed to enable investigation of the individual high temperature components. The test rig facilitated testing of the reformer, shift reactor, high temperature heat exchangers, natural gas desulfurization, burner and steam generation. The test apparatus includes a burner tester for combined and individual high temperature component testing. The skid has a steam system to provide the steam required for the reformer and shift testing. Also, the skid has four electric process heaters for heating various fluids to the desired test conditions. The control and analytical capabilities associated with the system include GC gas analysis, over 25 analog inputs, over 85 thermocouple inputs and a fully automated control system with remote capabilities. The gases used in this test include steam, natural gas, hydrogen, nitrogen, and air. The product of the test apparatus is syngas. The test rig uses the burners from the full size design to heat the reformer and related components similar to the production design. 


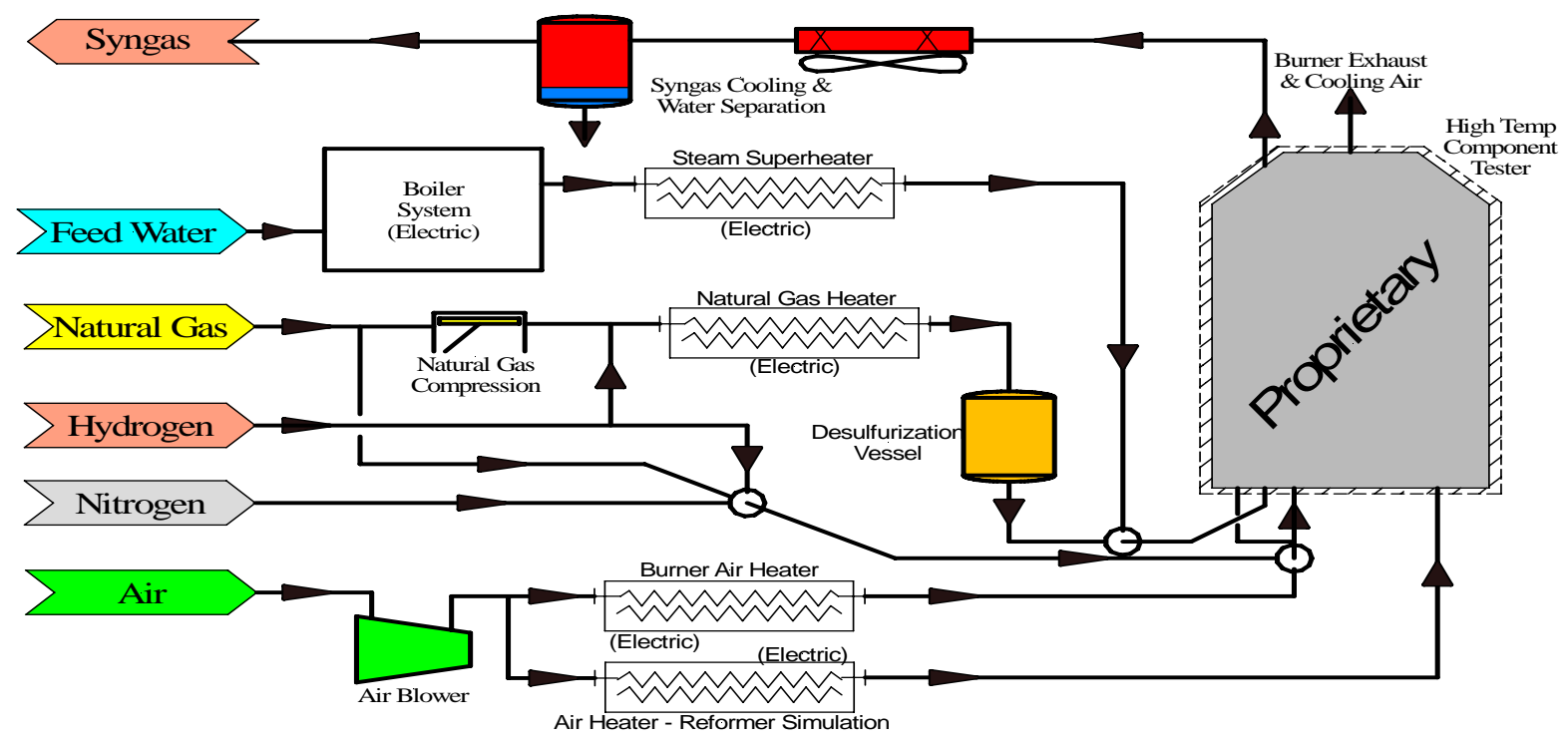

Figure 23. Process flow diagram for the full scale component test apparatus.

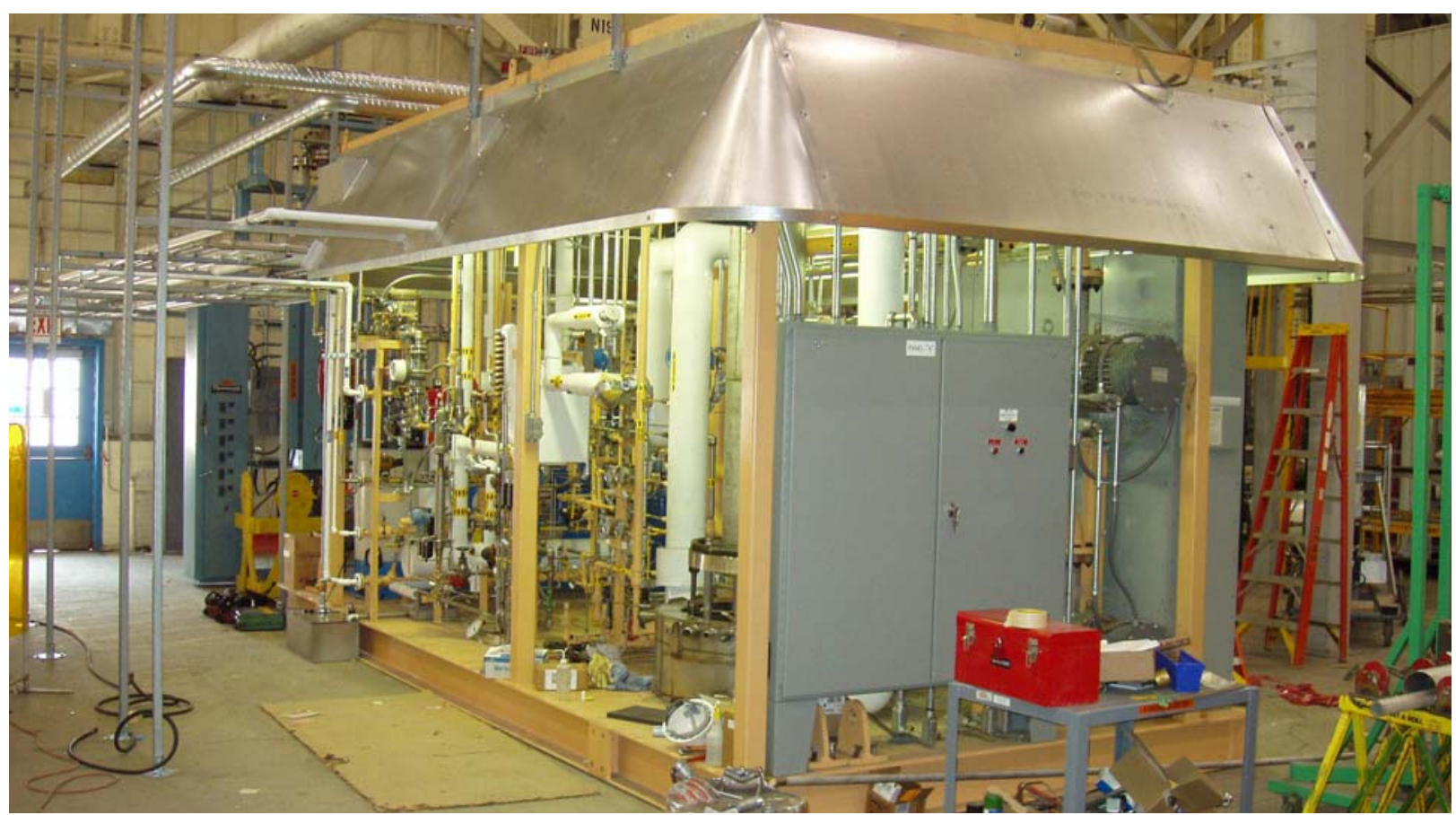

Figure 24. Small hydrogen system component test apparatus installed at Praxair. The test rig is capable of full scale testing of the system components as well as full analytical capabilities associated with each test.

A parametric study was conducted to understand the heat transfer properties inside the high temperature component. The parameters investigated were the fuel flow to the burner, the burner air flow rate, the burner air preheat temperature, the reformer feed flow rate, and the reformer feed preheat temperature. For the purposes of this investigation, process air was utilized to simulate the reformer feed. The fuel composition to the burner was $21 \%$ natural gas, $11 \%$ hydrogen, and $68 \%$ nitrogen for all experiments. This composition provided an accurate surrogate for PSA tailgas based on a comparison of molecular weight and Wobbe index. Prior 
to the initiation of testing, a preliminary evaluation of burner performance was conducted to understand parameters such as flame height and flame stability/uniformity.

Table 7 shows the approximate ranges of process conditions studied as well as the corresponding full scale design values. A matrix of the tests conducted is shown in table 8 . Individual tests included a series of single variable tests followed by a series of multivariable interaction tests. The testing sequences were structured using Six Sigma testing techniques. The data was analyzed and predictive models that included process variable interactions were developed. These models predict the heat transfer rate and temperature at any point in the reformer system as a function of any of the test parameter. The models are limited to the geometry configuration, but serve as a baseline as the system geometry is modified to adjust flow, temperature and heat transfer within the component. Representative data for the single variable tests are shown in figures 25-29. This data shows how individual parameters affect the heat transfer rate to the process air stream.

Table 7. Ranges of process conditions studied and full scale design values.

\begin{tabular}{|l|c|c|}
\hline Process Variable & Range Studied & Full Scale Design Value \\
\hline Burner Fuel Flow (SCFH) & $700-1200$ & 1572 \\
\hline Process Air Flow (SCFH) & $4100-8200$ & 3557 \\
\hline Burner Air Flow (SCFH) & $4100-8200$ & 7848 \\
\hline Process Air Preheat (deg F) & $375-650$ & 1062 \\
\hline Burner Air Preheat (deg F) & $375-670$ & 1043 \\
\hline
\end{tabular}


Table 8. Experimental matrix for the full scale component tester heat transfer testing.

\begin{tabular}{|c|c|c|c|c|c|}
\hline Test \# & Burner Fuel Flow (SCFH) & Process Air Flow (SCFH) & Burner Air Flow (SCFH) & Process Air Preheat (deg F) & Burner Air Preheat (deg F) \\
\hline 1 & 1001 & 4103 & 4100 & 375 & 377 \\
\hline 2 & 1002 & 8157 & 8200 & 652 & 668 \\
\hline 3 & 702 & 4100 & 4099 & 376 & 650 \\
\hline$\frac{5}{4}$ & 702 & 4100 & 8201 & 642 & 667 \\
\hline 5 & 998 & 8200 & 4096 & 650 & 379 \\
\hline 6 & 702 & 8200 & 8200 & 380 & 667 \\
\hline 7 & 1002 & 4102 & 8197 & 376 & 667 \\
\hline 8 & 1002 & 8039 & 4100 & 380 & 651 \\
\hline 9 & 702 & 8200 & 8200 & 650 & 386 \\
\hline 10 & 702 & 8200 & 4102 & 650 & 652 \\
\hline 11 & 1001 & 4108 & 8201 & 642 & 386 \\
\hline 12 & 702 & 8043 & 4099 & 380 & 379 \\
\hline 13 & 1002 & 8200 & 8200 & 380 & 386 \\
\hline 14 & 702 & 4103 & 8201 & 376 & 385 \\
\hline 15 & 702 & 4102 & 4100 & 642 & 377 \\
\hline 16 & 1002 & 4100 & 4100 & 643 & 651 \\
\hline 17 & 851 & 6151 & 6150 & 513 & 522 \\
\hline 18 & 1000 & 8190 & 8200 & 378 & 666 \\
\hline 19 & 999 & 4110 & 8195 & 373 & 384 \\
\hline 20 & 701 & 7992 & 4102 & 649 & 378 \\
\hline 21 & 701 & 8199 & 8200 & 379 & 385 \\
\hline 22 & 701 & 4087 & 8202 & 641 & 385 \\
\hline 23 & 702 & 4099 & 4098 & 642 & 650 \\
\hline 24 & 701 & 8026 & 4100 & 380 & 650 \\
\hline 25 & 702 & 8200 & 8199 & 650 & 667 \\
\hline 26 & 1000 & 7982 & 4100 & 650 & 651 \\
\hline 27 & 1000 & 8057 & 4106 & 378 & 377 \\
\hline 28 & 1000 & 8200 & 8200 & 650 & 386 \\
\hline 29 & 701 & 4096 & 8197 & 376 & 666 \\
\hline 30 & 1000 & 4101 & 4098 & 641 & 377 \\
\hline 31 & 1000 & 4096 & 8201 & 642 & 666 \\
\hline 32 & 1001 & 4100 & 4101 & 376 & 649 \\
\hline 33 & 701 & 4099 & 4100 & 375 & 377 \\
\hline 34 & 851 & 6147 & 6150 & 513 & 522 \\
\hline 35 & 702 & 4098 & 8201 & 642 & 666 \\
\hline 36 & 1000 & 7979 & 4097 & 649 & 379 \\
\hline 37 & 701 & 4100 & 4100 & 641 & 377 \\
\hline 38 & 1000 & 4098 & 8203 & 642 & 386 \\
\hline 39 & 701 & 4099 & 4099 & 376 & 650 \\
\hline 40 & 1000 & 4099 & 4101 & 375 & 377 \\
\hline 41 & 701 & 8200 & 4102 & 650 & 651 \\
\hline 42 & 701 & 4102 & 8196 & 375 & 385 \\
\hline 43 & 701 & 8200 & 8200 & 649 & 386 \\
\hline 44 & 701 & 8200 & 8200 & 380 & 666 \\
\hline 45 & 1000 & 8170 & 4100 & 380 & 651 \\
\hline 46 & 1000 & 8201 & 8200 & 650 & 667 \\
\hline 47 & 701 & 8070 & 4101 & 377 & 377 \\
\hline 48 & 1000 & 8199 & 8200 & 378 & 385 \\
\hline 49 & 1001 & 4096 & 8200 & 376 & 666 \\
\hline 50 & 1000 & 4100 & 4100 & 642 & 650 \\
\hline 51 & 851 & 6154 & 6150 & 516 & 522 \\
\hline 52 & 1200 & 7498 & 7508 & 558 & 290 \\
\hline 53 & 1198 & 7499 & 7503 & 559 & 386 \\
\hline 54 & 1199 & 7520 & 7498 & 559 & 478 \\
\hline 55 & 1198 & 7495 & 7497 & 559 & 573 \\
\hline 56 & 1197 & 7488 & 7487 & 559 & 665 \\
\hline 57 & 748 & 7514 & 7503 & 559 & 572 \\
\hline 58 & 822 & 7502 & 7503 & 560 & 572 \\
\hline 59 & 897 & 7498 & 7480 & 560 & 572 \\
\hline 60 & 972 & 7492 & 7501 & 559 & 572 \\
\hline 61 & 1048 & 7499 & 7502 & 559 & 572 \\
\hline 62 & 1122 & 7487 & 7502 & 559 & 572 \\
\hline 63 & 1199 & 7488 & 7497 & 559 & 572 \\
\hline 64 & 1272 & 7503 & 7500 & 559 & 572 \\
\hline 65 & 1348 & 7494 & 7496 & 559 & 572 \\
\hline 66 & 1423 & 7520 & 7503 & 559 & 572 \\
\hline 67 & 1197 & 7499 & 7502 & 559 & 572 \\
\hline 68 & 1199 & 7494 & 6998 & 560 & 571 \\
\hline 69 & 1200 & 7510 & 6507 & 560 & 570 \\
\hline 70 & 1202 & 7482 & 6013 & 560 & 569 \\
\hline 71 & 1198 & 7487 & 5515 & 560 & 568 \\
\hline 72 & 1198 & 7517 & 5039 & 560 & 566 \\
\hline 73 & 1199 & 7513 & 7506 & 285 & 570 \\
\hline 74 & 1197 & 7506 & 7508 & 379 & 570 \\
\hline 75 & 1196 & 7516 & 7494 & 469 & 570 \\
\hline 76 & 1199 & 7475 & 7510 & 558 & 572 \\
\hline 77 & 1199 & 7512 & 7516 & 648 & 572 \\
\hline 78 & 1198 & 5979 & 7513 & 557 & 573 \\
\hline 79 & 1197 & 6509 & 7505 & 558 & 573 \\
\hline 80 & 1198 & 7002 & 7498 & 559 & 573 \\
\hline 81 & 1198 & 7498 & 7491 & 559 & 572 \\
\hline 82 & 1198 & 8003 & 7506 & 559 & 572 \\
\hline
\end{tabular}




\section{Burner Fuel Flow vs Heat Transfer Rate}

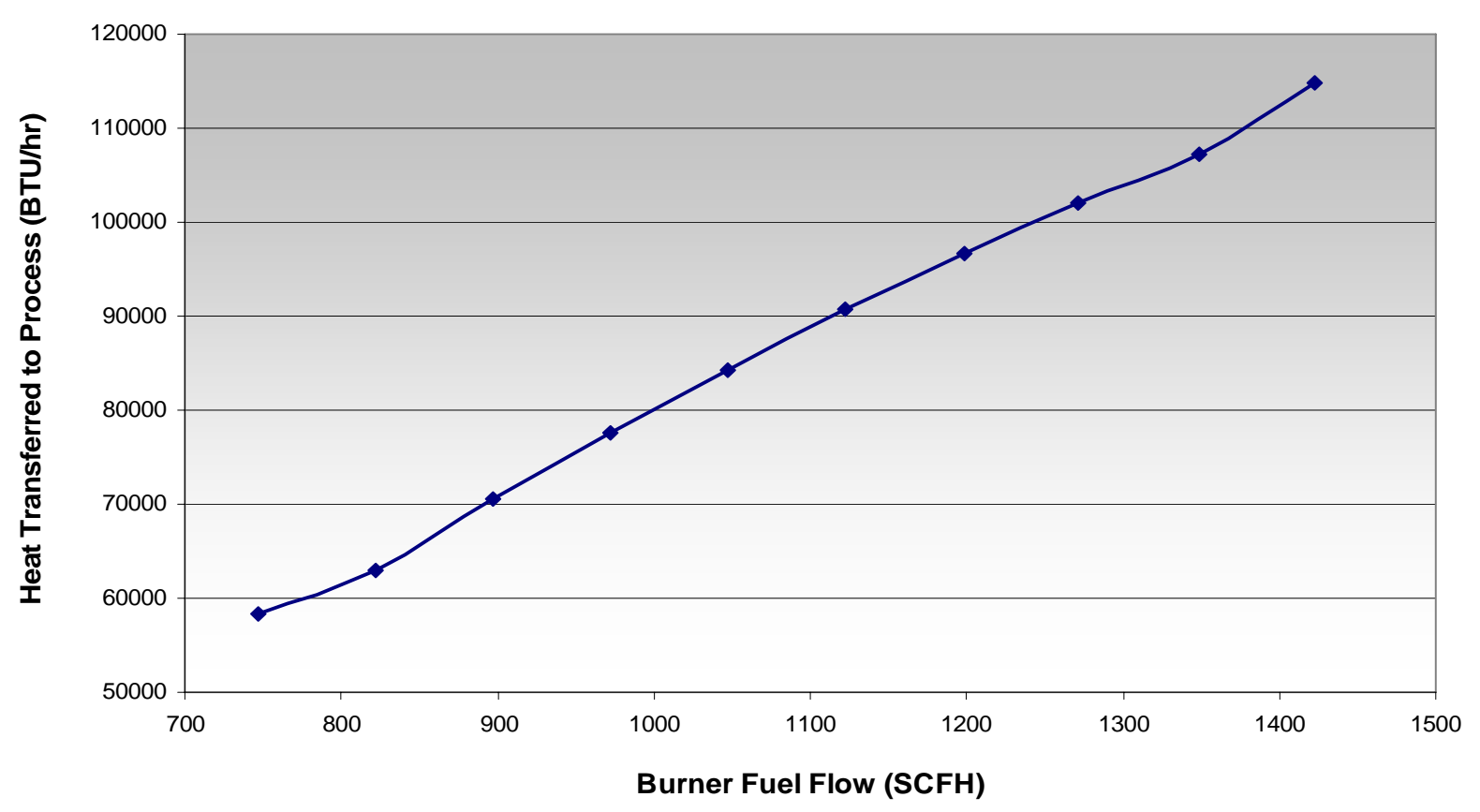

Figure 25. Burner fuel flow effect on the heat transfer rate

\section{Process Air Flow vs Heat Transfer Rate}

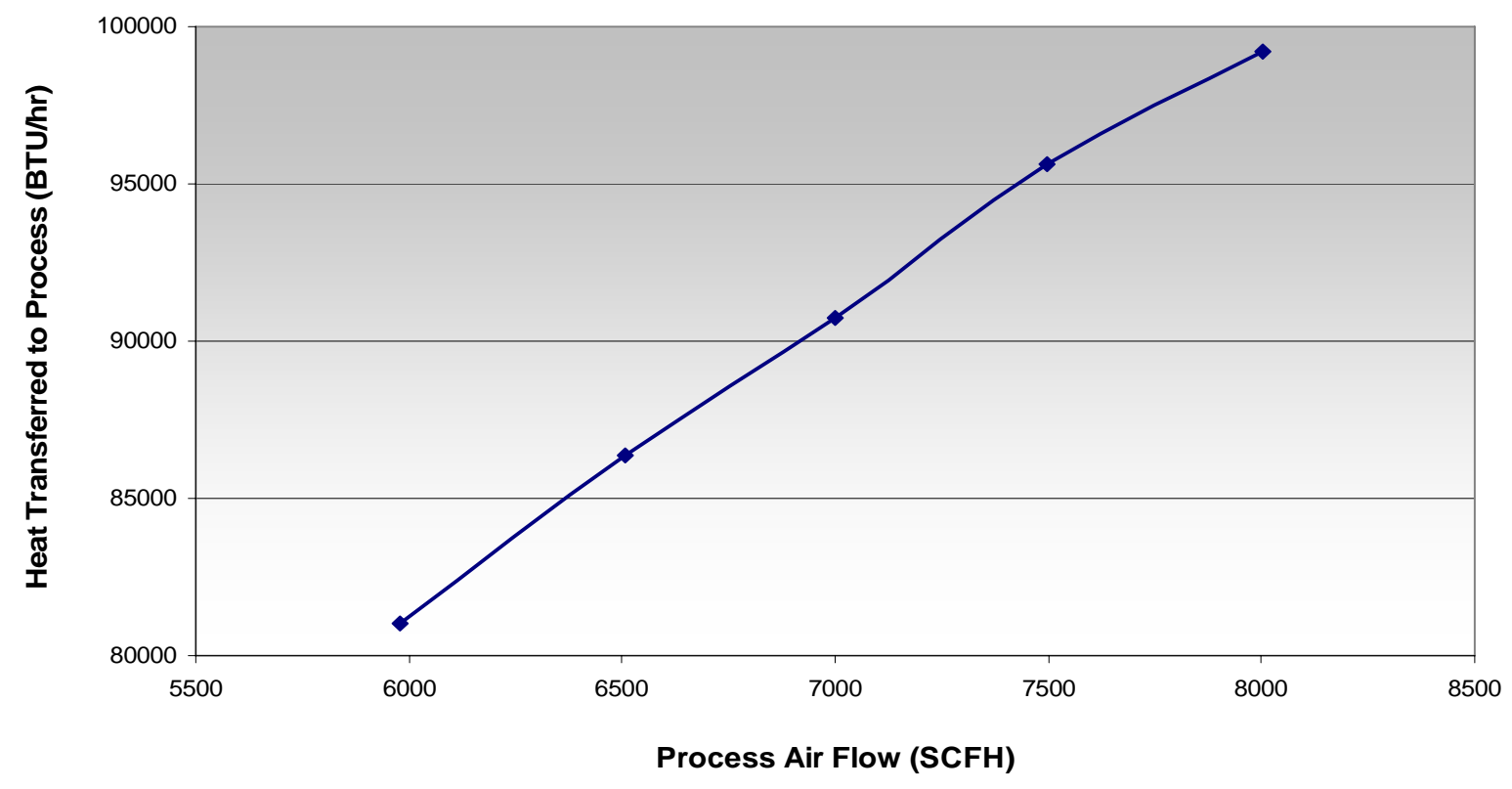

Figure 26. Process air flow effect on heat transfer rate 


\section{Burner Air Flow vs Heat Transfer Rate}

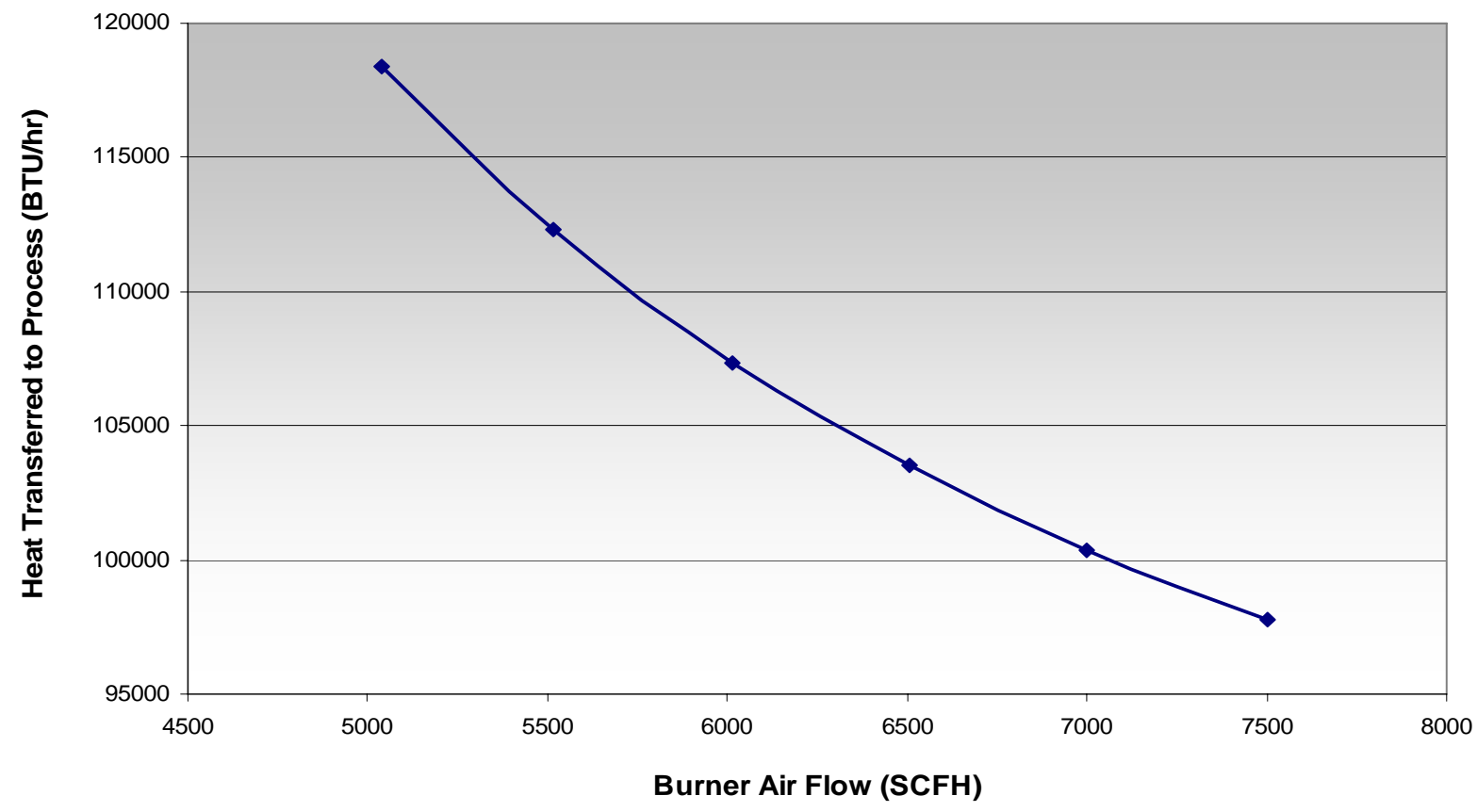

Figure 27. Burner air flow effect on heat transfer rate.

Process Air Preheat vs Heat Transfer Rate

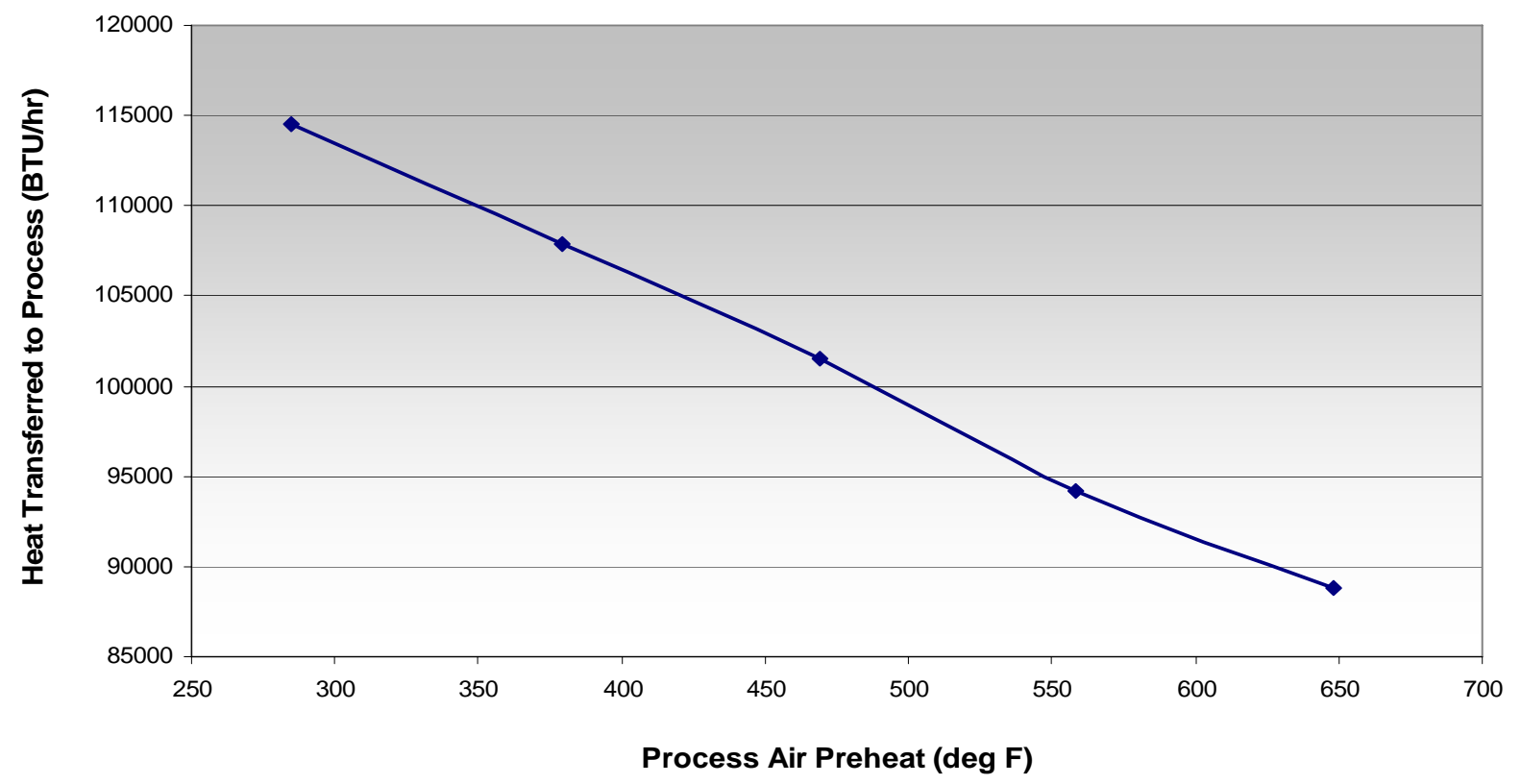

Figure 28. Process air preheat effect on heat transfer rate. 


\section{Burner Air Preheat vs Heat Transfer Rate}



Figure 29. Burner air preheat effect on heat transfer rate to process air.

For the single variable testing, the base case consisted of a burner fuel flow of $1200 \mathrm{SCFH}, \mathrm{a}$ process air flow of 7500 SCFH, a burner air flow of 7500 SCFH, a process air preheat of $560 \mathrm{~F}$, and a burner air preheat of $570 \mathrm{~F}$. From the data above, it is clear that the heat transfer rate is directly proportional to the burner fuel flow, process air flow, and burner air preheat and inversely proportional to the burner air flow and process air preheat.

In addition to the parametric studies mentioned above, additional tests were conducted to investigate the addition of shielding positioned around the reformer component. A matrix of the tests conducted to study the effects of shielding is shown in table 9 . The primary purpose of the shielding was to decrease the heat transfer rate near the burners in order to prevent overheating of the reformer tube walls. Figure 30 shows representative data of the temperature profiles on the burner and process sides of the high temperature component with and without the presents of the shielding. As expected, the addition of shielding has a significant effect of the temperature profile on the burner side of the high temperature component. Specifically, the addition of the shielding reduces the heat transfer rate near the burners, causing the burner exhaust gas temperature to climb at a much faster rate relative to the case where shielding is not present. The addition of shielding does however cause a drop in the overall heat transfer rate to the process air over the length of the component. 
Table 9. Experimental matrix for the full scale component tester heat transfer testing with shielding.

\begin{tabular}{|c|c|c|c|c|c|}
\hline Test \# & Burner Flow (SCFH) & Cooling Air Flow (SCFH) & Burner Air Flow (SCFH) & Cooling Air Preheater (deg F) & Burner Air Preheater (deg F) \\
\hline 1 & 851 & 6160 & 6148 & 513 & 522 \\
\hline 2 & 1002 & 4099 & 4095 & 374 & 376 \\
\hline 3 & 1000 & 8150 & 8186 & 649 & 666 \\
\hline 4 & 700 & 4105 & 4102 & 641 & 377 \\
\hline 5 & 703 & 4106 & 8193 & 642 & 666 \\
\hline 6 & 1001 & 7830 & 4106 & 649 & 378 \\
\hline 7 & 703 & 8183 & 8155 & 380 & 666 \\
\hline 8 & 999 & 4110 & 8168 & 376 & 666 \\
\hline 9 & 1002 & 7867 & 4093 & 378 & 650 \\
\hline 10 & 701 & 8095 & 8182 & 649 & 386 \\
\hline 11 & 700 & 7811 & 4102 & 649 & 649 \\
\hline 12 & 1002 & 4099 & 7963 & 641 & 384 \\
\hline 13 & 678 & 7869 & 4102 & 378 & 376 \\
\hline 14 & 997 & 7888 & 8137 & 379 & 384 \\
\hline 15 & 678 & 4101 & 7937 & 374 & 384 \\
\hline 16 & 676 & 4084 & 4102 & 641 & 376 \\
\hline 17 & 999 & 4094 & 4098 & 641 & 649 \\
\hline 18 & 850 & 6150 & 6153 & 513 & 521 \\
\hline 19 & 757 & 6178 & 6156 & 512 & 521 \\
\hline 20 & 890 & 6084 & 6153 & 512 & 521 \\
\hline 21 & 698 & 4081 & 8197 & 642 & 666 \\
\hline 22 & 1020 & 7974 & 4103 & 648 & 377 \\
\hline 23 & 694 & 4105 & 4103 & 640 & 377 \\
\hline 24 & 983 & 4153 & 8188 & 641 & 385 \\
\hline 25 & 694 & 4151 & 4101 & 374 & 648 \\
\hline 26 & 1010 & 4107 & 4090 & 374 & 377 \\
\hline 27 & 694 & 7843 & 4109 & 649 & 650 \\
\hline 28 & 691 & 4159 & 8210 & 365 & 384 \\
\hline 29 & 694 & 8154 & 8207 & 648 & 386 \\
\hline 30 & 852 & 6151 & 6150 & 513 & 522 \\
\hline 31 & 999 & 4103 & 4100 & 375 & 376 \\
\hline 32 & 999 & 7697 & 8088 & 649 & 665 \\
\hline 33 & 701 & 4110 & 4099 & 375 & 647 \\
\hline 34 & 701 & 4106 & 7781 & 642 & 666 \\
\hline 35 & 999 & 7831 & 4101 & 649 & 377 \\
\hline 36 & 702 & 7657 & 7979 & 380 & 665 \\
\hline 37 & 1023 & 4104 & 7753 & 376 & 666 \\
\hline 38 & 1022 & 7845 & 4104 & 380 & 650 \\
\hline 39 & 701 & 7579 & 7986 & 649 & 386 \\
\hline 40 & 701 & 7828 & 4102 & 649 & 649 \\
\hline 41 & 1022 & 4094 & 7820 & 641 & 384 \\
\hline 42 & 701 & 7885 & 4097 & 378 & 377 \\
\hline 43 & 1023 & 7620 & 7924 & 380 & 384 \\
\hline 44 & 701 & 4102 & 7764 & 374 & 384 \\
\hline 45 & 701 & 4101 & 4100 & 641 & 377 \\
\hline 46 & 1002 & 4097 & 4100 & 642 & 650 \\
\hline 47 & 850 & 6152 & 6149 & 512 & 522 \\
\hline
\end{tabular}




\section{High Temperature Component Temperature Profiles}

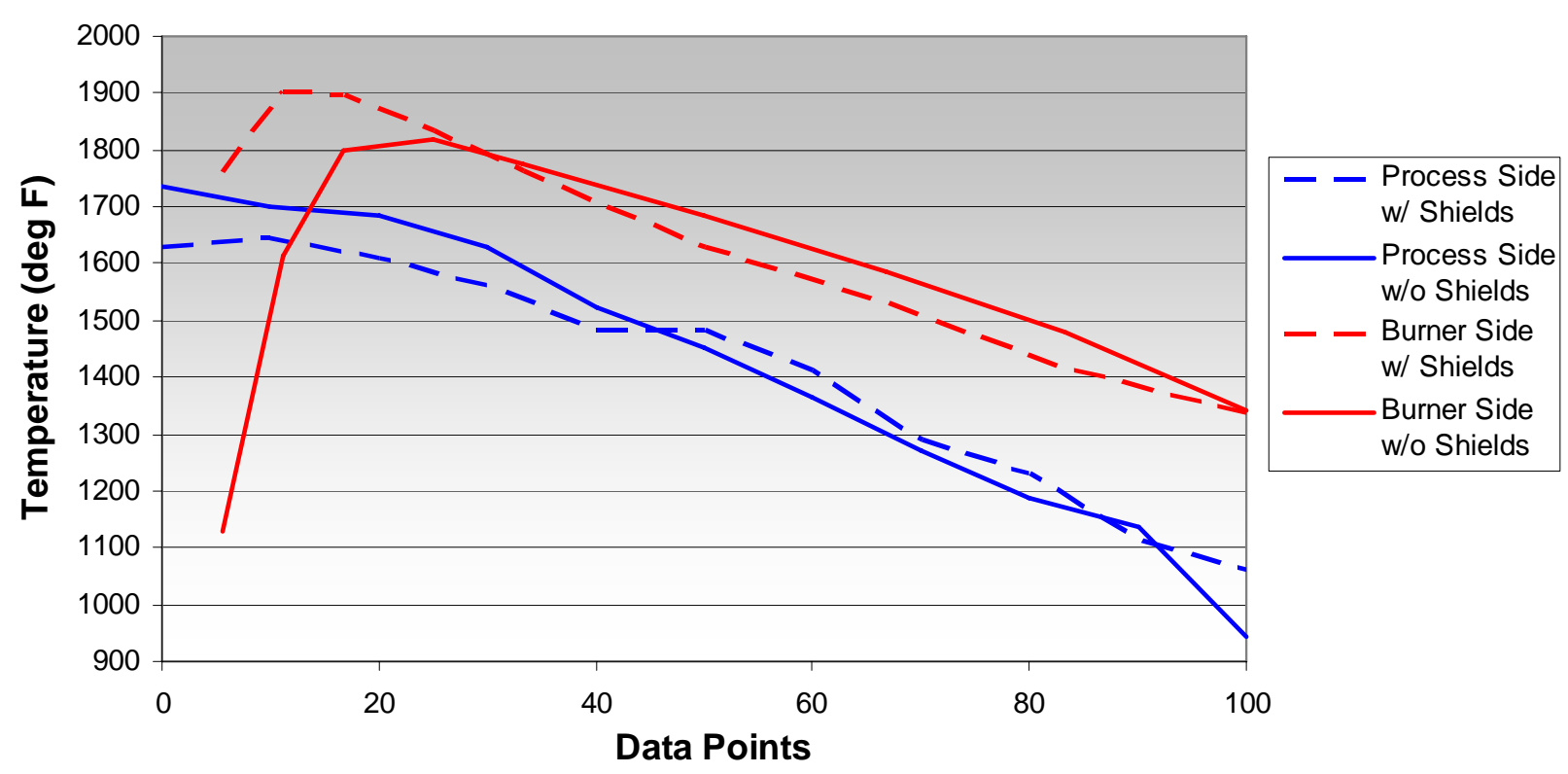

Figure 30. High temperature component temperature profiles. The ' 0 ' on the $x$-axis refers to the bottom of the component and the '100' refers to the top of the component.

The highest measured heat transfer rate observed during this testing program was approximately $118,000 \mathrm{BTU} / \mathrm{hr}$. This is significantly lower than the full scale design requirement of $235,400 \mathrm{BTU} / \mathrm{hr}$. The heat transfer rate will increase significantly with the use of the actual reformer feed as compared to process air. Because the reforming reaction is endothermic, the heat consumed by the reactions will result in lower temperatures inside the tubes thus increasing the driving force for heat transfer.

The positive results of the testing showed that the commercially available low cost burners are functioning within the system design parameters using simulated PSA tailgas as the fuel. In addition, the proximity of the burners to the reformer component is sufficient to not cause flame impingement or hot spots on the reformer component. This result means that the overall size of the reformer chamber, as well as the overall component, did not need to increase. An increase in the size of the component would have likely resulted in an increase in the overall cost of the component. The burners were also able to provide uniform heat input throughout the reformer section (after geometry modifications were incorporated to more evenly distribute the heat).

In addition to the testing described above, several other testing programs were completed as described below.

An initial burner test was completed at the burner supplier in mid December 2004. The burner test involved a low cost commercial burner system that is generally fueled by natural gas or propane, but in our case is using a mixture of $\mathrm{CO}, \mathrm{CH} 4, \mathrm{H} 2$ and $\mathrm{CO} 2$ to simulate the typical burner fuel (tailgas from the PSA) used in an SMR based system. The burner system, using this fuel, functioned very well with even flame distribution and no issues with the simulated PSA tailgas fuel. A full size burner was purchased and installed in the test rig described above.

Tests have been completed related to the materials of construction of the high temperature component. These tests include forming the various alloys in the shape of the components and 
testing them by thermal cycling from ambient to operating temperature. The alloys that met all the requirements of these tests were then tested for compatibility using simulated process gas at the operating temperature in the component tester as described above.

A PSA system developed for the GE-EERC Auto Thermal Reforming (ATR) DOE program was tested and optimized at UC Berkeley and ownership of the prototype has been transferred from the GE-EERC program to this program. The PSA is currently being stored at Praxair in Tonawanda, NY.

\section{4 - Economics.}

The system economic model was updated continually throughout Phase II. The cost models reflect the parameters per the updated DOE technical plan for hydrogen production. The baseline for the cost models is a 20 year analysis period, 10\% IRR after taxes, 1.9\% inflation, $75 \%$ utilization factor, 0.08/kWhr power and \$5.00/MMBTU natural gas. Since the system being developed in this program is designed to produce significantly less hydrogen than the DOE baseline system, a second line (red in the graph) has been added to estimate where the LCHPP system would rate at the higher production levels. The current estimated cost of hydrogen from the LCHPP system is shown in figure 31 below. All modifications resulting from the testing and modeling efforts of Phase II have been incorporated into the costs presented below.

\section{H2 Cost vs Units Produced and H2 Flowrate}

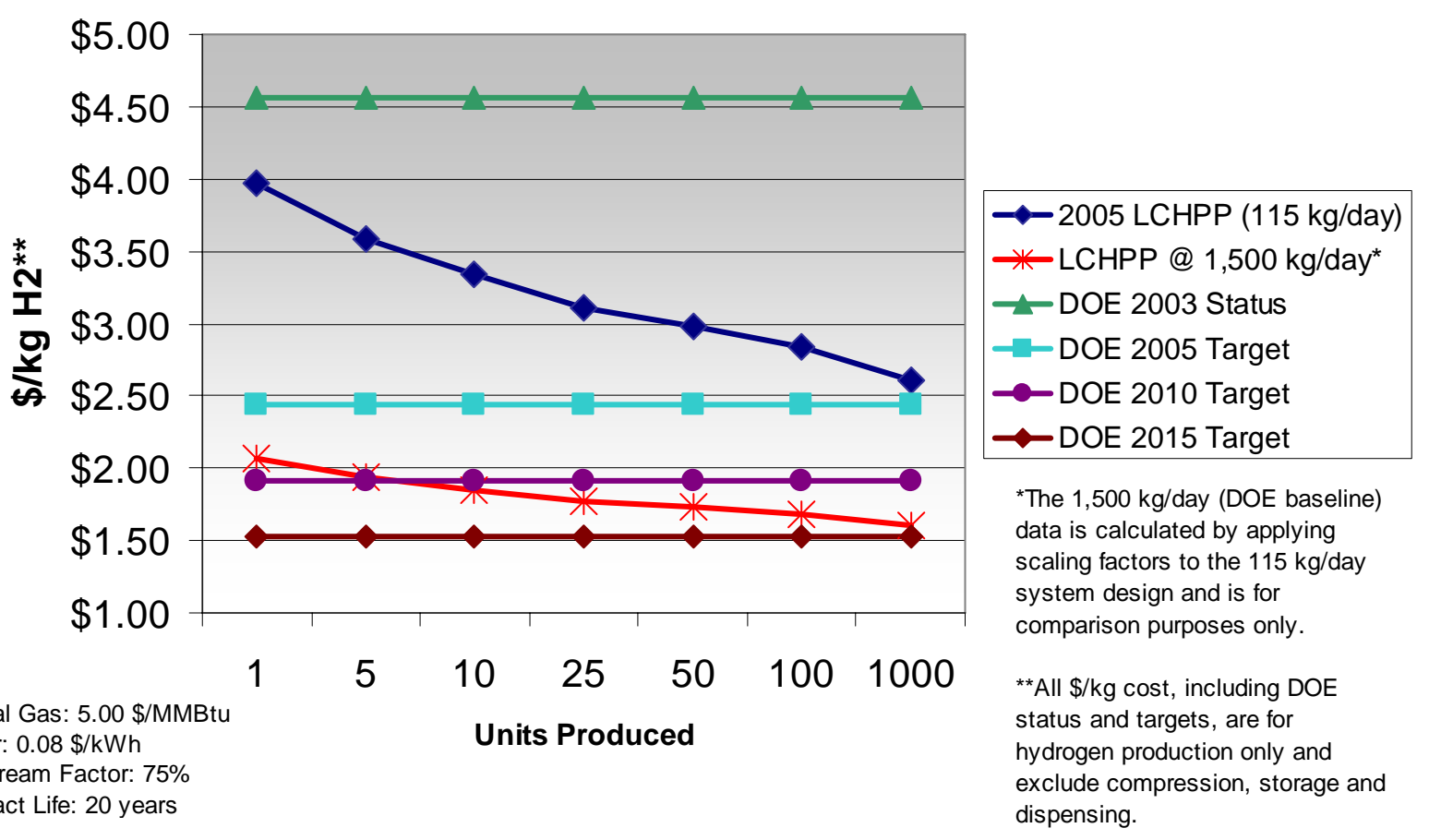

Figure 31. Unit hydrogen cost for the $4.8 \mathrm{~kg} / \mathrm{h}$ system versus units produced. The DOE baseline is calculated at a production level of 500 units produced. ${ }^{*} A l l \$ / k g$ cost, including DOE status and targets, are for hydrogen production only and exclude compression, storage and dispensing. 


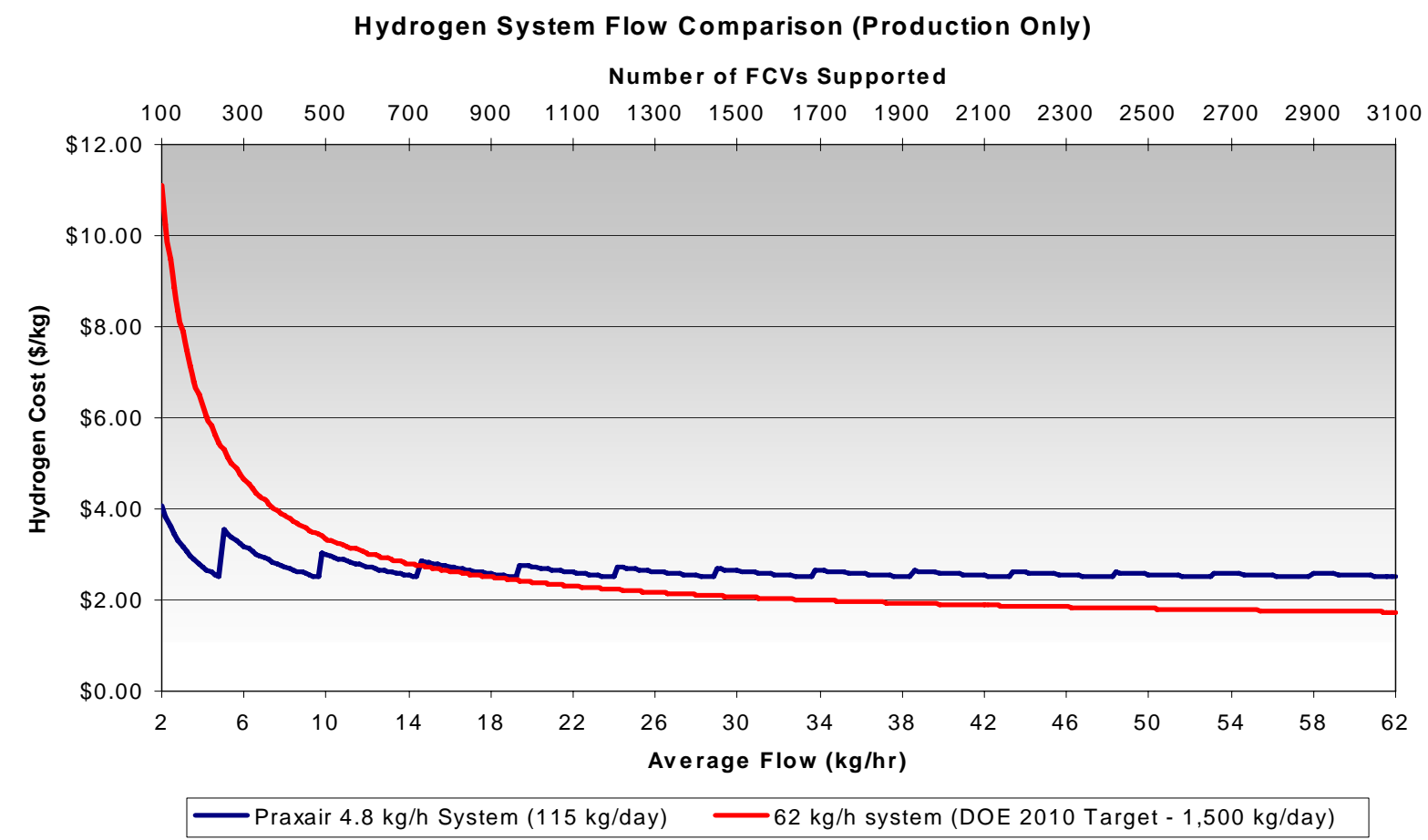

Figure 32. Comparison of multiple Praxair $4.8 \mathrm{~kg} / \mathrm{h}$ system versus the DOE target system (each notch in the graph represents the addition of a $4.8 \mathrm{~kg} / \mathrm{h}$ system.

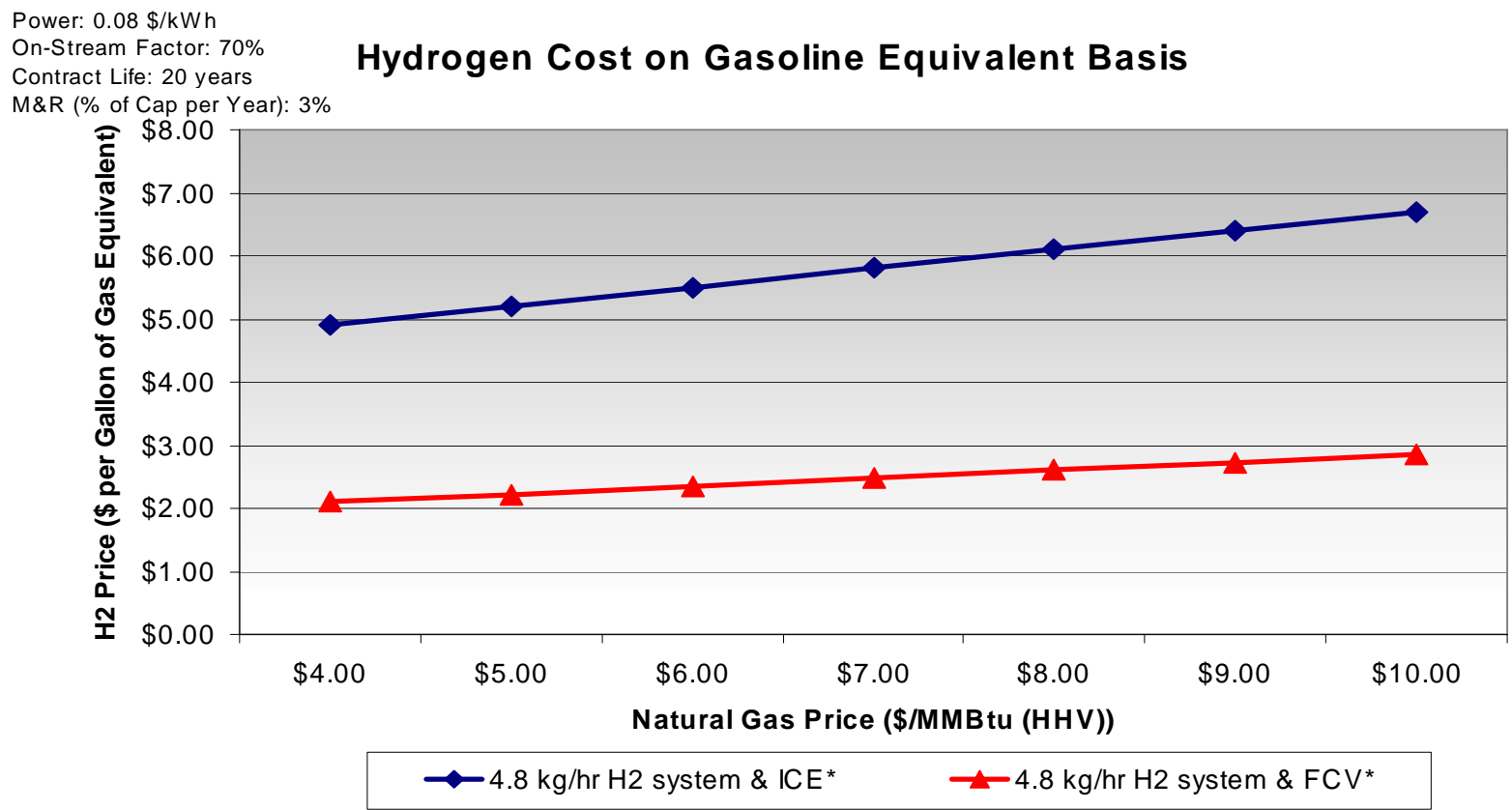

Figure 33. Comparison of hydrogen cost on a gallon of gasoline equivalent basis. Assumes a gasoline hybrid powered car baseline mileage of 43 miles per gallon (MPG), a 75\% efficiency increase for hydrogen FCVs on an energy basis and a $25 \%$ efficiency decrease for hydrogen fueled ICE automobiles. 


\subsection{Phase I and II Conclusions}

- Applying DFMA principles to the overall design significantly lowered the cost to produce hydrogen at capacities of 2.4 to $12 \mathrm{~kg} / \mathrm{h}$.

- A complete hydrogen generating system producing $4.8 \mathrm{~kg} / \mathrm{h}$ can be packaged in a single skid that is small enough to easily fit into a typical parking space.

- A new benchmark appears possible for the cost of hydrogen produced from current process technologies (i.e. SMR, \& PSA purification).

- Component testing indicated the system is viable and a full scale prototype could be confidently built and operated (Phase III of the program).

\subsection{Phase III - Prototype Testing and Fueling Station System Integration}

Full scale component testing was continued after Phase II funding was discontinued by the DOE. Reforming tests were conducted at 1/8 of the design capacity, i.e. 1/8 of the reformer tubes were filled with the commercial reforming catalyst, while the remaining tubes contained process air. The testing proved that sufficient heat transfer to the catalyst filled reformer tubes was present to achieve desired methane conversions. The testing also verified the performance of the desulfurization component present on the test unit. Initial reformer testing was conducted utilizing an external steam boiler that was located on the test unit as a means of providing process steam. Additional tests were conducted to investigate internal steam generation as well. These tests proved that sufficient internal steam generation was achieved to satisfy full scale design requirements.

The Phase III proposal was submitted to the DOE in January 2007. The proposed scope of Phase III was to design, construct and operate a full size prototype hydrogen production system. The prototype system would initially be operated and evaluated at a controlled location and subsequently be integrated into a fueling station as part of the technical evaluation/demonstration of the technology for fueling hydrogen vehicles. The main system components that were individually developed and testing in the previous phases of the program would be integrated into the complete prototype system. The prototype would include natural gas compression, reformer, shift reactor, water treatment, steam generation, heat exchangers, PSA purification and all other related components required for the commercial system. Phase III also proposed tasks related to component life and material testing using the test rigs developed in Phase II. Along with hardware and system testing, the computer process models, DFMA analysis, economic models and design documents for the commercial system would continue to be updated. Additional DFMA evaluations related to the skid packaging and auxiliary equipment would be completed in Phase III. In addition to the production unit development, Phase III also included tasks for the evaluation and demonstration of product compression to 10,000 psig and integration/operation of the system at a hydrogen fueling station. The DOE has not awarded or provided any funding for the Phase III activities as presented in the Praxair proposal. 


\subsection{Patents}

US patent number 7,500,999 was issued on March 10, 2009 for the high temperature component design.

\subsection{Publications / Presentations}

- Annual DOE program review meeting and reports 2001-2007.

- A paper and presentation titled 'DFMA Approach to Reducing the Cost of Hydrogen Produced from Natural Gas' was given to the Society of Automotive Engineers (SAE) in October 2003.

- A presentation titled 'Using DFMA to Reduce the Cost of Hydrogen from Small Steam Methane Reformer Based Systems' was given to the Hydrogen Production \& Storage Forum in Washington, DC in December 2003.

- A paper and presentation titled "DFMA Approach to Reducing the Cost of Hydrogen Produced from Natural Gas" was given to the Design For Manufacturing and Assembly (DFMA) forum in June 2006.

- A paper and presentation titled "Development of a Cost-Effective Hydrogen Production System for Vehicle Fueling Stations" was given to the ASME International Mechanical Engineering Congress and Exposition in November 2007.

\subsection{Networks/Collaborations}

ISO - Praxair is an active participant in the development of numerous ISO standards for design, safety, testing and analysis of hydrogen and hydrogen generating equipment. Praxair has members on ISO Technical Committee 197 - WG 9 developing ISO 16110-1 \& 2: "Hydrogen generators using fuel processing technologies" and ISO Technical Committee 197 - WG 12 developing ISO 14687-2 "Hydrogen Fuel - Product Specification - Part 2: PEM fuel cell applications for road vehicles".

\subsection{References}

AC Transit, December 14, 2000. Engineering, Design, and Project Management of Hydrogen Refueling Facility and Modifications of Maintenance Facilities, Request for Qualification No. 2000-716.

California Air Resources Board (CARB) 2001. http://Www.arb.ca.gov/msprog/zevprog/2001rule/propmods.pdf

Chemical Marketing Reporter, January 29, 2001, p. 37.

Heydorn, B. and Zuanich, J. 1998. Market Assessment Small Scale Hydrogen Generation, prepared by SRI Consulting for Gas Research Institute, GRI-97/0395.

Thomas, C. E., James, B. D., Kuhn, I. F. Jr., Lomax, F. D. and Baum, G. N. 1997. Hydrogen Infrastructure, DOE Report No. 47-2-R31148. 
Thomas, C. E., James, B. D., Lomax, F. D. and Kuhn, I. F. Jr. 2000. "Fuel Options for the Fuel Cell Vehicle: Hydrogen, Methanol or Gasoline?", International Journal of Hydrogen Energy, 25:551-567.

Weiss, M. A., Heywood, J. B., Drake, E. M., Schafer, A. and AuYeung, F. F. 2000. "On the Road in 2020", Energy Laboratory Report \# MIT EL 00-003, Massachusetts Institute of Technology. http://web.mit.edu/energylab/www/pubs/el00-003.pdf

Manufacturer website data available for the Honda Civic and Accord hybrid vehicles 2007.

U.S. DOE Multi-Year Research, Development and Demonstration Plan 2006. 